\title{
A Methodology for Wellbore Stability Analysis of Drilling into Presalt Formations: A Case Study from Southern Iran
}

\author{
Raoof Gholami ${ }^{1}$, Minou Rabiei ${ }^{2}$, Brent Aadnoy ${ }^{3}$, Vamgh Rasouli ${ }^{2}$ \\ 1- Department of Petroleum Engineering, Curtin University, Malaysia \\ E-mail: Raoof.Gholami@Curtn.edu.my \\ 2- Department of Petroleum Engineering, University of North Dakota, USA \\ 3- Department of Petroleum Engineering, University of Stavanger, Norway
}

\begin{abstract}
Drilling into presalt formations has been a long-standing issue due to the rapid changes in the diameter of the borehole during drilling operations either because of creep or wash-out dissolution. There have been many studies on characterization of salts, with many mathematical models being presented to estimate the pressure induced due to the squeezing salt sheets. However, the results of none of these models have been fully validated against real field data and some recommendations have been made based on numerical simulations. In this study, attempts were made to introduce a methodology based on damage mechanics for wellbore stability analysis of a wells drilled in the southern part of Iran. The results obtained indicated that the presence of a thick salt layer in the well has resulted in significant wellbore closure in the intervals above the reservoir section. It was also found that the salt exhibits viscoelastic behaviour during drilling due to the homogeneous temperature which has not reached the threshold limit of viscoplastic boundary. A complicated change in the stress regime was also observed which could be linked to the existence of the thick salt layer or presences of a fault crossing the well. Therefore, it is recommended to further validate this model in other wells using the methodology presented.
\end{abstract}

\section{Introduction}

In the past few years, due to the limited conventional reservoirs left undiscovered, the oil and gas industry has targeted deep reservoirs under large, thick salt formations which are known as presalt reservoirs (Greenhalgh et al. 2012; Chitale et al. 2014). Unlike subsalt reservoirs, to reach the presalt reservoirs, the well has to drill through the whole section of salt (Garland et al. 2012; Thompson et al. 2015) which is not often easily achieved due to the complex behaviour of salt. Salt formations are recognized as evaporate rocks composed primarily of halite, creeping as a viscous or power-law fluid over geologic time when pressure and temperature prevail (Hudec and Jackson, 2009). As a result, drilling operations in the regions dominated by massive salt bodies face many challenges including rapid wellbore closure, stuck pipe, casing collapse and cement disintegration (Willson, 2005). The rate of closure, however, may vary from days and weeks to months and years, depending on the mud pressure and temperature as well as creep behaviour, which is a function of grain size, mineralogy, water content, depth and strain rate. 
There are often two assumptions included in the studies carried out for stability analysis of wellbores drilled into salt formations, which may need reconsiderations. The first assumption is that stress anisotropy does not exist around a salt layer (Cheatham and McEver, 1964), due to its viscous behaviour, which makes salt incapable of sustaining shear stress (Carcione et al., 2006). It should be noted that salt is at least 15 times stiffer than water and as a result it would need stress differential for creeping and squeezing the wellbore wall. The second assumption is that the pore pressure in the salt formation is equal to the overburden stress (Willson and Fredrich, 2005; Zhang et al., 2008). This assumption is mainly based on the fact that salt does not have any porosity and permeability (Dusseault et al., 2004), which makes it hard to run any formation tester to determine salt's pore pressure. As a result, the pressure of the pore fluid in salt is estimated by a linear interpolation of the pore pressure at the top and bottom of salt layers, which cannot be correct due to the poor communication capability of salt rocks (Rios and Roegiers, 2012).

Therefore, presalt drilling operations are very challenging because: 1 ) the mud pressure cannot be balanced due to the pore pressure of zero in impermeable salts (Zhang et al. 2008; Weijermars et al., 2014a), 2) geological formations trapped by salt bodies may generate an overpressure zone (Schoenherr et al. 2007; Israel et al. 2008), 3) uncased (open) wells drilled in salt are closed by ductile creep at different rates, depending on the moisture and heat conduction along the wellbore (Dusseault et al. 2004), 4) additional forces are applied to the horizontal flow inside the mobile low-viscosity layers of salt, which may cause shear deformation of wellbores (Weijermars and Jackson 2013). As a result, there have been several strategies developed to mitigate wellbore closure while drilling through salt. For instance, the conventional approach is to drill quickly through salt layers and keep the mud cool to retard creep (Dusseault et al. 2004). Reaming and jarring might also be required, on these occasions (Chatar et al. 2010). Oil-based mud (OBM) prevents wellbore dissolution but cannot slow down the wellbore closure unless it can be kept cooled during circulation (Dusseault et al. 2004). Undersaturated water-based muds (WBMs) is a good option in thin salt intervals to mitigate the creep and wellbore closure. For thicker salt intervals, however, the rate of creep increases with depth and, thus, it would be hard to balance closure with dissolution. Overbalanced drilling and applying a higher pressure than the one posed by the creeping salt can also slow down the wellbore closure, but the margin of the Maximum Allowable Annulus Pressure (MAASP) can be easily reached, causing a significant mud loss and catastrophic blow-out. It should also be noted that salt causes significant perturbations to the stress magnitude and may rotate the direction of principal stresses within formations, which further complicates the wellbore stability analysis in salts (Weijermars et al., 2014b).

Therefore, a careful drilling optimization approach must be practiced to increase the success and mitigate the risk of drilling through creeping salt sheets. Conventionally, wellbore stability analysis is done by considering elastic-rock stresses (Kirsch 1898; Zoback 2008), where stresses around the wellbore drilled through salts are obtained by the Kirsch equations (Weijermars et al. 
2013; 2014a). In viscoelastic salt sheets, stresses applied due to the salt-creep can be evaluated by determination of closure rate of open wellbores (Fossum and Fredrich 2002; Willson et al. 2005; Carcione et al. 2006; Zhang et al. 2008; Liu et al. 2011; Weijermars et al. 2013). However, none of these models have been completely validated against real field data and only few recommendations have been made based on numerical simulations. In this study, a methodology is proposed based on damage mechanics for stability analysis of wells drilled through presalt formations. A real case study from a well drilled in the southern part of Iran is also brought to show the application of the methodology proposed for prediction of the strain rate induced by salt during drilling.

\section{Field of Study}

\subsection{Geological Settings}

The study field is located in the Zagros folded Belt of Iran, which has one of the largest petroleum reservoirs in the world (Molnar, 2006). This belt is recognized by its NW-SE trend orientation as the south-westerly boundary of the Zagros orogen near the Persian Gulf. The reservoir, Asmari limestone, in this field, is capped by the Gachsaran formations which are basically evaporate formations consisting mainly of anhydrite and salt (Alavi 2004; Bahroudi and Koyi, 2003). Gachsaran formations have shown to have complex physical and geomechanical behaviours in this field, based on the issues experienced during drilling and production such as lost circulation, kicks, stuck pipe, and casing collapse. It seems that these issues manifest at the interfaces of the rigid and ductile members, e.g. anhydrite and salt (Rolf et al., 2006; Gorjian et al., 2013). As a result, geomechanical characterization of the Gachsaran formations has been the subject of many studies in order to either evaluate their integrity during and after enhanced oil recovery (EOR) (Zoveidavianpoor et al., 2012) or finding solutions to prevent further issues during drilling or production stages (Dusseault et al., 2001; Rolf et al., 2006; Gorjian et al., 2013).

\subsection{Drilling}

The well of this study, which is referred to as Well A, was planned to go through Gachsaran formations and reach a total depth of $4115 \mathrm{~m}$ to produce from Asmari limestone reservoir. The completion design and the formations crossed during drilling this well are shown in Figure 1 . The properties of the water based mud used during drilling are summarised in Table 1. 


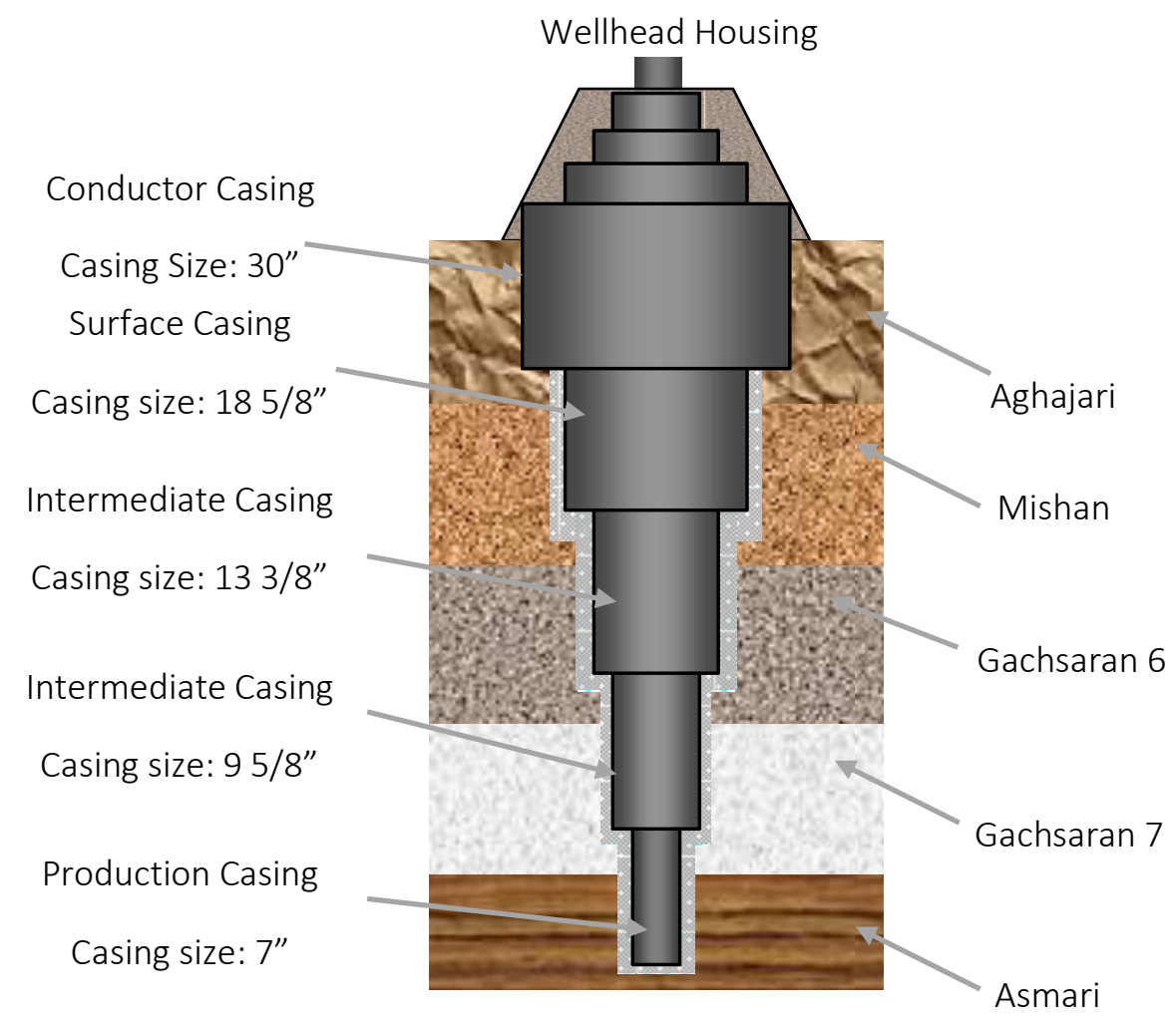

Figure 1: Schematic presentation of the completion and stratigraphy in Well A

Table 1: Water based mud characteristics used to drill through different formations

\begin{tabular}{|c|c|c|c|c|c|}
\hline Formations & $\begin{array}{c}\text { Formation } \\
\text { Type }\end{array}$ & $\begin{array}{c}\text { Plastic } \\
\text { Viscosity } \mathbf{( C P )}\end{array}$ & $\begin{array}{c}\text { Yield Point } \\
\left(\mathbf{l b} / \mathbf{1 0 0} \mathbf{f t}^{\mathbf{2}} \mathbf{)}\right.\end{array}$ & $\mathbf{p H}$ & $\begin{array}{c}\text { Mud Weight } \\
\text { (PPG) }\end{array}$ \\
\hline Aghajari & Marl and Sand & 5 & 30 & 10.5 & 8.6 \\
\hline Mishan & Marl & 10 & 10 & 10.5 & 11.3 \\
\hline Gachsaran 7 & Anhydrite & 30 & 12 & 9.5 & 13.3 \\
\hline Gachsaran 6 & Halite & 75 & 25 & 9.5 & 19.4 \\
\hline
\end{tabular}

As it is seen from Table 1, the mud weight at the interval of Gachsaran 6 formation, which is basically a halite formation with a viscosity of $10^{15}$ to $10^{19} \mathrm{~Pa} \mathrm{~s}$, was increased to 19.4 PPG in order to prevent the wellbore closure during drilling. Figure 2 shows the formation types, conventional logs, mud weight, borehole condition and completion design of the well after drilling.

Looking at this Figure, it seems that the high mud weight of 19.4 PPG used to drilling through Gachsaran 6 formation was not capable of preventing wellbore closure induced by the salt creep. This might be due to the elastoplastic behaviour of salt formations in a short time scale (4 to 40 days). In fact, wells drilled through salts are subject to both elastic and creep stresses, where the elastic stress may relax in less than 100 days if the viscosity of salts is less than $10^{16} \mathrm{~Pa} \mathrm{~s}$ (Weijermars et al., 2013). However, the deviatoric stress applied on the wellbore due to the viscous-creep characteristics of salts does not relax as long as the salt is flowing. 


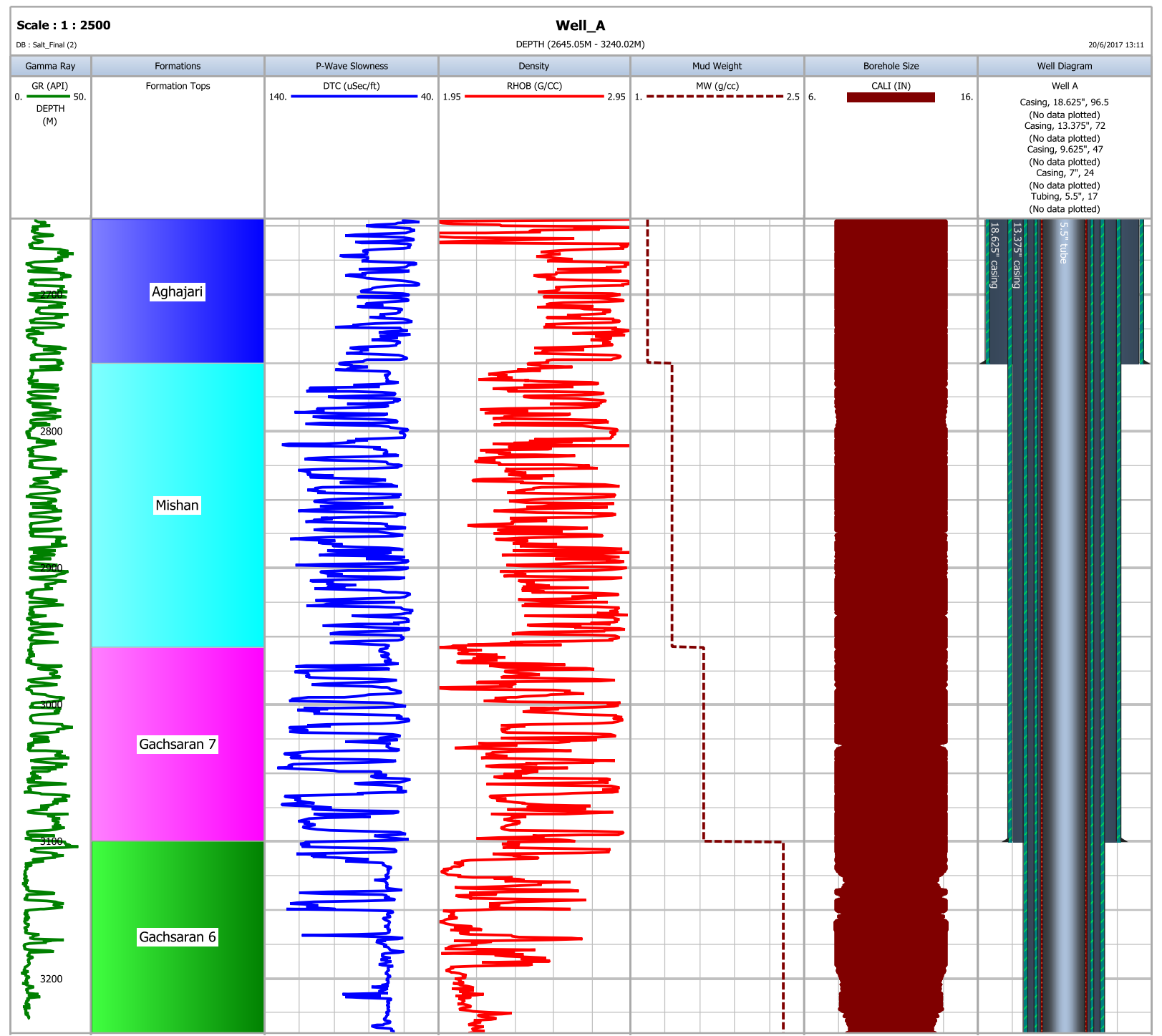

Figure 2: Formations type, conventional logs, mud weight, borehole condition and completion design of Well $A$

\section{Salt-Creep Modelling}

\subsection{Creep}

Creeping salt is a potential drilling risk, and stability analysis of wellbores must consider both elastic stress (Kirsch, 1898; Zoback, 2008) and superposed salt-creep stresses. Shear stresses caused by the ductile creep in salt bodies may reach $100 \mathrm{MPa}(14,504 \mathrm{psi})$. As a result, the design of structures, specially casing, against a complicated phenomenon such as creep requires a deep understanding of salt behaviour. The situation becomes more complex when the effect of temperature is included into the analysis due to its significant impact on the salt creep.

Creep is assumed to develop in three stages: 1) primary or reduced creep, which is also known as the strain hardening stage, 2 ) secondary or stationary creep, where softening processes such 
as recovery and recrystallization takes place and 3) tertiary or accelerated creep, where salt rupture may take place (Andrade, 1910). Figure 3 shows these three stages in the strain-time plot. It should be noted that salt does exhibit elastic behaviour at the early stage of loading, but creep dominates when pressure and temperature reach certain values.

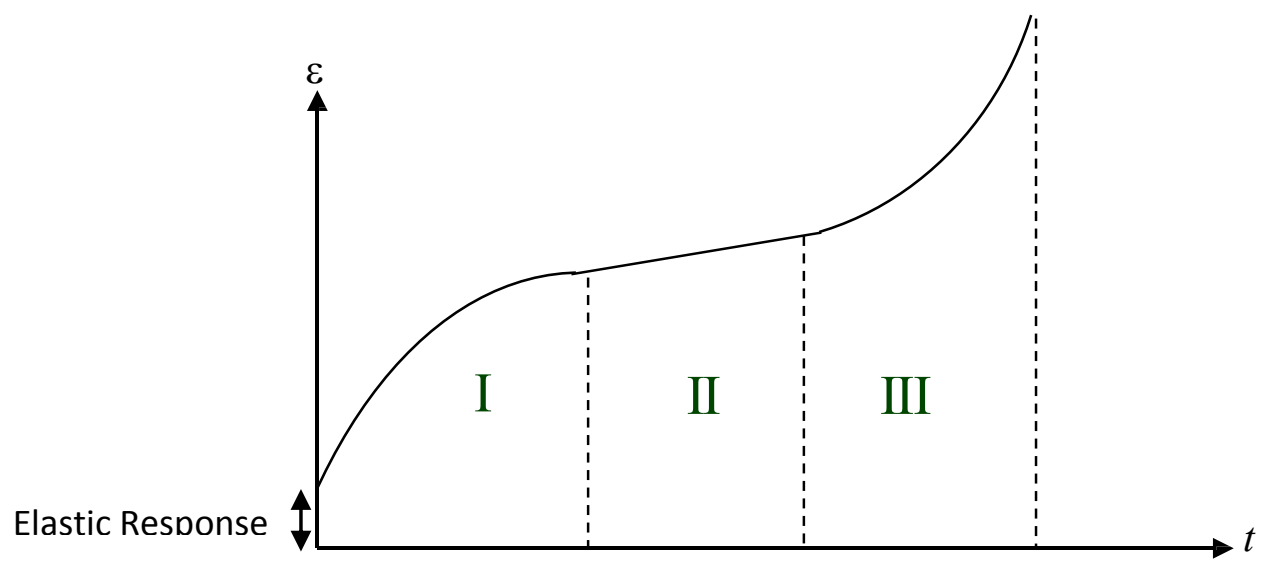

Figure 3: Conventional strain-time curve of creep behaviour observed in salt formations

\subsection{Creep Formulation}

According to the creep behaviour presented in Figure 3, the strain induced by salt can be divided into three parts, addressed as:

$$
\varepsilon=\varepsilon^{e l}+\varepsilon^{c r}+\varepsilon^{p l},
$$

where $\varepsilon^{\mathrm{el}}, \varepsilon^{\mathrm{cr}}$ and $\varepsilon^{\mathrm{pl}}$ are the elastic, creep and plastic strains, respectively. The creep strain, according to damage mechanics, can then be further divided into primary (relaxation, $\varepsilon^{\mathrm{p}}$ ), secondary (steady state, $\varepsilon^{\mathrm{s}}$ ), and tertiary (damage, $\varepsilon^{t}$ ) strains, where the tertiary strain is only observed in cavern storage sites due to the severe cyclic loading (Wang et al., 2014). Thus, the general strain deformations posed by a salt formation during drilling can be written as:

$$
\varepsilon=\varepsilon^{e l}+\varepsilon^{p}+\varepsilon^{s}
$$

Assuming that salt is an isotropic formation with a linear viscoelastic response to the applied stresses, for the purpose of this study, the Voigt-Kelvin model (Meyers and Chawla, 1999) was used to explain the salt behaviour under the elastic and primary creep stage. This is mainly because the classical Kelvin-Voigt viscoelastic solid could be viewed as a mixture of a linearized elastic solid and a linearly viscous fluid. This model consists of a linear spring element and a linear dashpot element which are connected in parallel as shown in Figure 4. 

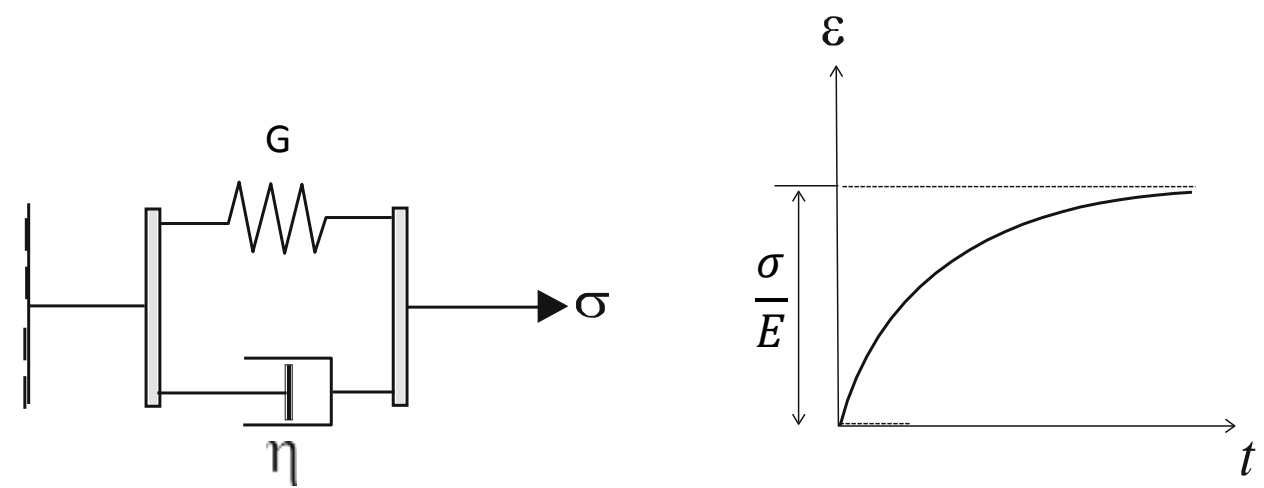

Figure 4: Voigt-Kelvin model: a mechanical scheme (linear viscous fluid) (left); and the creep strain at a constant stress input (linear elastic solid) (right)

The original version of the Voigt-Kelvin, after integration is written as (Meyers and Chawla, 1999):

$$
\varepsilon^{e l}=\frac{\sigma}{E}\left[1-\exp \left(-\frac{E}{\eta} t\right)\right]
$$

where $\sigma$ is the (maximum hoop) stress applied on salt, $E$ is the Young's modulus of salt, $\eta$ is the viscosity of salt and $t$ is the time.

It should be noted, however, that salt is a solid and unsaturated rock, where shear modulus $(G)$ can be a better representative of viscosity than Young's' modulus. Hence, the Voigt-Kelvin model was modified by replacing the Young's modulus with the shear modulus in the exponential part as:

$$
\varepsilon^{e l}=\frac{\sigma}{E}\left[1-\exp \left(-\frac{G}{\eta} t\right)\right]
$$

To determine the steady state (secondary) creep, it is important to determine the type of creep exhibited by salt. it should be recalled that salt may show plastic deformation under normal conditions and exhibits diffusional flow or power-law creep if temperature prevails. To determine the type of creep, the deformation-mechanism map developed by Graham and Walles, (1961) and Frost and Ashby (1982) can be used. This map is schematically shown in Figure 5, where types of creep is determined based on the normalized equivalent (von-Mises) stress $\left(\sigma_{\mathrm{eq}} / G\right)$ and the homologous temperature $\left(T / T_{m}\right)$, where $G$ is the shear modulus and $T_{m}$ is the melting temperature. 


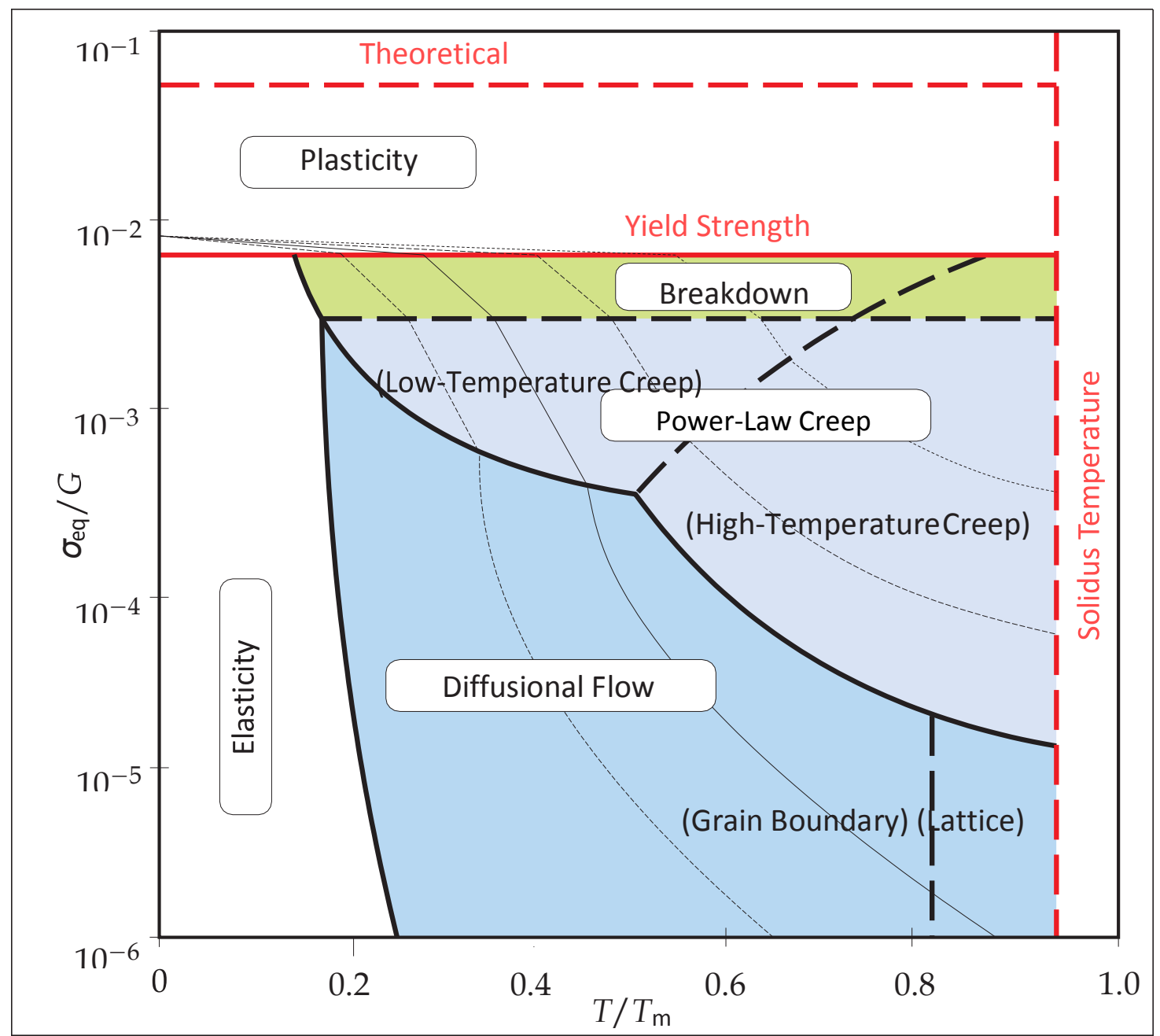

Figure 5: Schematic presentation of the deformation-mechanisms map (modified after Gorash, 2008)

Table 2 gives the deformation mechanisms and the corresponding response functions under different conditions shown in the deformation-mechanism map. Therefore, by plotting the stress applied against the temperature of the bottomhole, one can recognize the creep strain dominated at the strain softening stage.

Table 2: Deformation mechanisms and their corresponding response functions

\begin{tabular}{|c|c|c|}
\hline Deformation Mechanism & Response Function & Reference \\
\hline Power-Law & $\varepsilon^{c r}=A \exp \left(-\frac{Q}{R T}\right) \sigma^{n} t$ & Frost and Ashby, (1982) \\
\hline Diffusional Flow & $\varepsilon^{c r}=A \exp \left(-\frac{Q}{R T}\right) \sigma t$ & Lifshitz, (1963) \\
\hline Linear + Power Law & $\varepsilon^{c r}=\exp \left(-\frac{Q}{R T}\right) \sinh A \sigma t$ & Dyson and McLean, (2001) \\
\hline Power-Law Breakdown & $\varepsilon^{c r}=\exp \left(-\frac{Q}{R T}\right) \exp C \sigma t$ & Sherby and Burke, (1967) \\
\hline
\end{tabular}




\section{Mechanical Earth Modelling (MEM)}

A Mechanical Earth Model (MEM) is built to represent the mechanical properties of rocks together with in-situ stress, pore pressure and temperature of the subsurface layers. It is often used to understand rock's behaviours during drilling and completion stages, and to determine the casing setting depth, mud weight windows for safe drilling, fluid flow detection, and many other operational parameters (Barton et al., 1998). A MEM provides details of rock characteristics, their deformation mechanisms and borehole conditions based on wireline logs, mud logs, cuttings, laboratory tests and in-situ measurements such as Leak-Off Tests (LOT), minifrac tests and repeat formation tests (RFT).

MEM is often initiated by determination of elastic properties from physics equations, followed by characterization of strength and pore pressure from existing correlations and estimation of insitu stress from developed correlations/equations. The results obtained are then calibrated against representative core and field data to ensure that the MEM has sufficient accuracy. Further details of a MEM and geomechanical parameters determined for wellbore stability analysis of vertical and deviated wellbores drilled in isotropic and anisotropic formations are comprehensively discussed in the studies carried out by Gholami et al., (2014, 2015a, 2015b, 2017).

\subsection{MEM for Salt}

\subsection{Elastic properties}

Sonic logs (P-wave and S-wave slowness) together with the density log are often used to determine the elastic parameters of rocks (Fjaer et al., 2008). The parameters obtained are, however, at least three to four times bigger than the real values and must be converted to their corresponding static values using different correlation proposed based on rock types and geological settings (Zoback, 2007). The results must then be calibrated against the laboratory or field measurements to ensure their accuracy.

For the purpose of this study, dynamic elastic parameters were converted to static ones using correlations proposed by Wang, (2000). However, there was no core samples available to perform any mechanical tests and calibrate the results. Nevertheless, the static elastic parameters of halite have been reported frequently in recent studies, where it is highlighted that the Young's modulus of salt reaches the peak value of $\sim 11 \mathrm{GPa}$ at a confining pressure of $40 \mathrm{MPa}$ and elevated temperature of $85^{\circ} \mathrm{C}$ (Du et al. 2012). The third track of Figure 6 shows the static Young's modulus calculated in this study. From this figure, it is seen that the static values of the Young's modulus are within the expected range of common salt rocks at the existing temperature and pressure of the Well. The temperature profile is shown in the last track of Figure 6 and the confining pressure (in-situ stress) profile is shown in Figure 7. It should be noted that the temperate profile was calibrated against the data obtained from the quartz gauge sensor of the Modular Dynamic Formation Tester, depicted in Figure 8. 


\subsection{Compressive Strength}

Uniaxial compressive strength (UCS) of rocks can be estimated in correlation with the velocity, density, porosity or elastic characteristics. The results should be calibrated against lab measurements for validation purposes.

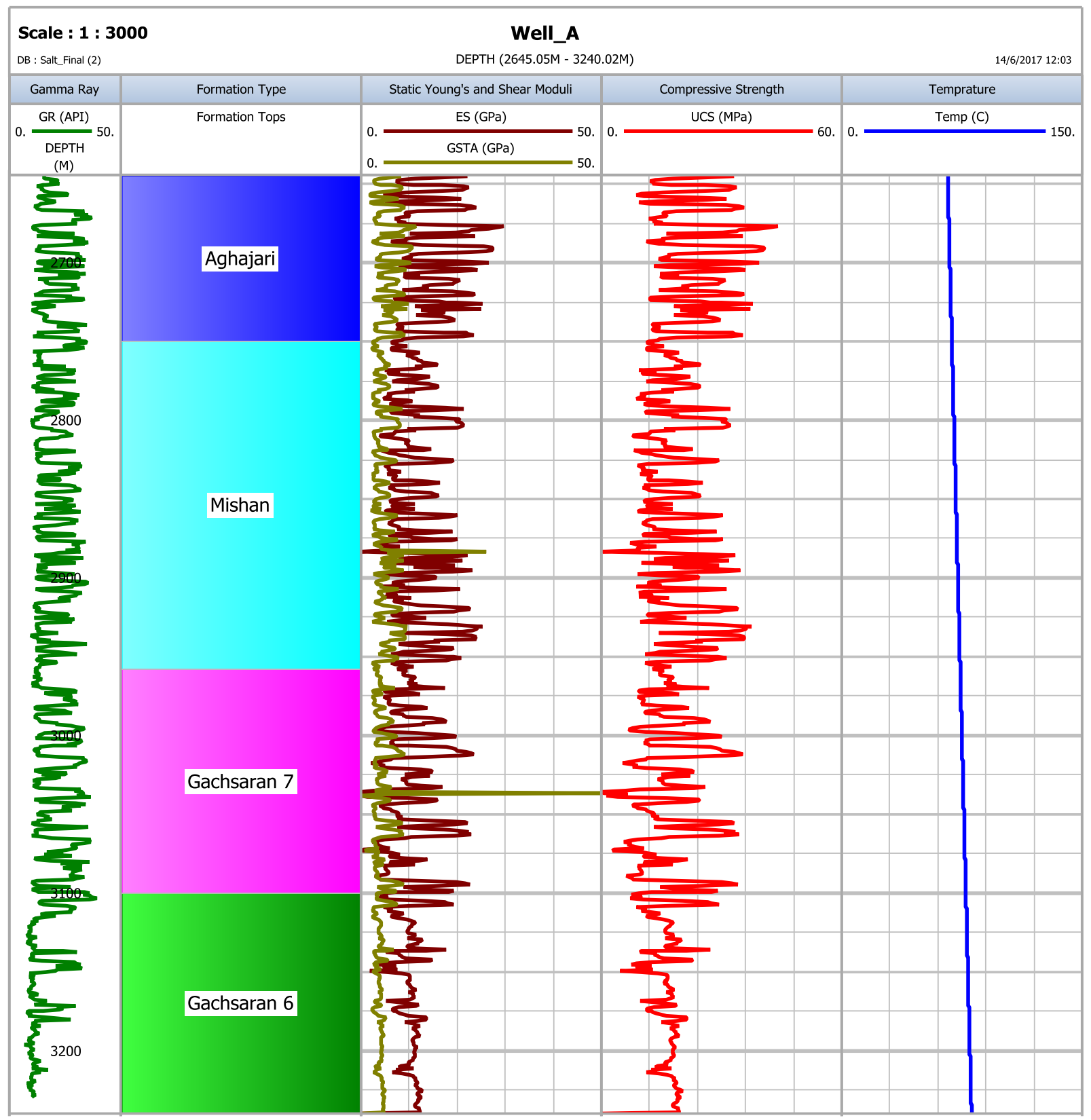

Figure 6: Elastic, strength and temperature variations of formations in Well A

In this study, the UCS of formations in Well A were estimated using different well-known correlations such as those presented by Bradford (1998), Horsrud (2001), Golubev and Rabinovich (1976). The predictions provided by these correlations were then calibrated against the lab mechanical tests conducted by Mehrgini et al., (2016) on Gachsaran samples. According 
to Mehrgini et al., (2016), the UCS of salt varies from 30 to $40 \mathrm{MPa}$, depending on the depth from which they were taken. These values had a good match with the strength estimated by Bradford (1998) correlation for Gachsaran 6 and Gachsaran 7 formations.

\subsection{Pore pressure}

Estimation of pore pressure is important as it is the main parameter used to design the mud weight such that no kick or blow-out will be experienced during drilling. This parameter may have a normal hydrostatic or an extremely abnormal magnitude, depending on the type of formations or geological settings. As a result, an accurate prediction of pore pressure would be critical before and during drilling to reduce the chance of any catastrophic incidents (Zhang, 2011).

There are two ways to estimate the pore pressure of formations: 1 ) direct measurements using formation testers or drill stem tools, which, apart from their cost, are not capable of providing any results in tight formations, 2 ) indirect methods which are based on mathematical equations or empirical correlations (Gutierrez et al., 2006), but must be calibrated once selected.

Among different approaches developed to indirectly estimate the pore pressure, Eaton's equation (Eaton, 1975) was used for the purpose of this study, which is basically an equation developed for shale rocks. This equation was used because like shale, Aghajari (marl), Mishan (marl), Gachsaran 7 (anhydrate) and Gachsaran 6 (halite) have a very low permeability. The procedure of using Eaton's equation is extensively presented by Gholami et al., (2017). The third track of Figure 7 displays the pore pressure profile, estimated using the Eaton's equation after fitting the Normal Compaction Trend (NCT) curve to the sonic log.

To calibrate the results, the pore pressure measurements made by the formation tester (i.e., MDT tester of Schlumberger) at the reservoir (Asmari) interval, shown in Figure 8, were used. It should be noted that due to the low permeability of other formations, there was not any other record of pore pressure measurements in the Well at any other intervals. However, the MDT data could still be useful. In fact, as it is seen in the top section of Figure 8 before $3450 \mathrm{~m}$, the pore pressure is still hydrostat which is the same pressure estimated by the Eaton equation at the top formations in Well A. This leads to an interesting conclusion that unlike what was expected, there is a fluid communication between the formations at the top and bottom of the Gachsaran salt layer as otherwise the pore pressure could not be hydrostatic.

It was also observed from Figures 7 that the estimated pore pressure is very well constrained within the range of the mud used for drilling. Considering the fact that there was no report of any kick incidents in the well, the estimated pore pressure seems reasonably correct as it is less than the mud weight used in the well (see the third track of Figure 7). It should also be recalled that the pore pressure inside the salt (Gachsaran 6) formations should be close to zero because it is a very tight formation (Aadnoy et al., 2009).

\subsection{In-situ Stresses}

The in-situ stress plays a crucial role in the drilling and production stages where well design and planning, wellbore stability, hydraulic fracturing design, risk assessment for fault reactivation and 
subsidence prevention are done (Bratton et al., 2004; Gholami et al., 2017. Rasouli et al., 2011). At field scale, it is assumed that the in-situ stresses have three principal components known as vertical, maximum horizontal and minimum horizontal stresses. The vertical stress can be estimated by integration of bulk density, gravitational acceleration and depth, with an average gradient of $1 \mathrm{psi} / \mathrm{ft}$. Estimation of the horizontal stresses, on the other hand, is not very straight forward. The common approach is to use different equations/correlations developed in the past decades to estimate the magnitudes of horizontal stress (e.g., Hubbert and Willis, 1957; Matthews and Kelly, 1967; Aadnoy and Loyeh, 2011). Regardless of the method used, without calibration against the field scale measurements such as minifrac or leak-off test (LOT), significant uncertainty will be involved in the calculations of in-situ stress magnitudes (Zoback et al., 2003).

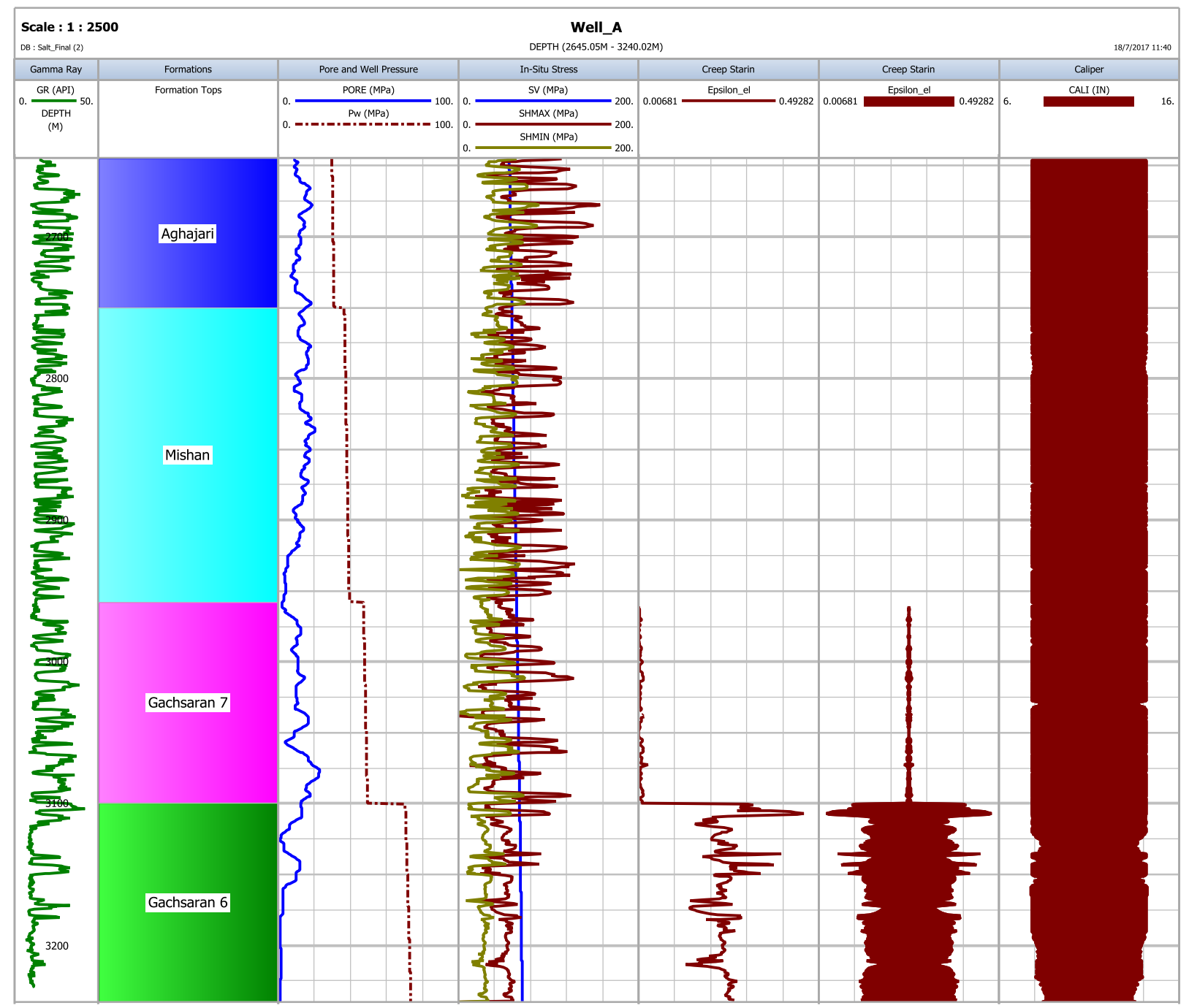

Figure 7: Pore and mud pressure as well as the vertical and two horizontal stresses and the creep strain values in Well $A$

Poro-elastic equations are perhaps the most commonly used models for estimation of the magnitude of horizontal stresses based on their proven applications in vertical and directional 
wells (Gholami et al., 2015a, Gholami et al., 2015b, Gholami et al., 2017; Rasouli et al., 2011), although the stress polygon approach has also shown its application under many circumstances (Gholami et al., 2015b). However, stress polygon can only be used in the intervals where the magnitude of the minimum horizontal stress is known from LOT, minifrac or hydraulic frac tests. For the purpose of this study, the poro-elastic equations were used to estimate the magnitude of the horizontal stresses $A$ and the results were presented in the fourth track of Figure 7. To calibrate, the XLOT test carried out at the casing shoe of $3800 \mathrm{~m}$ was used, as shown in Figure 9.
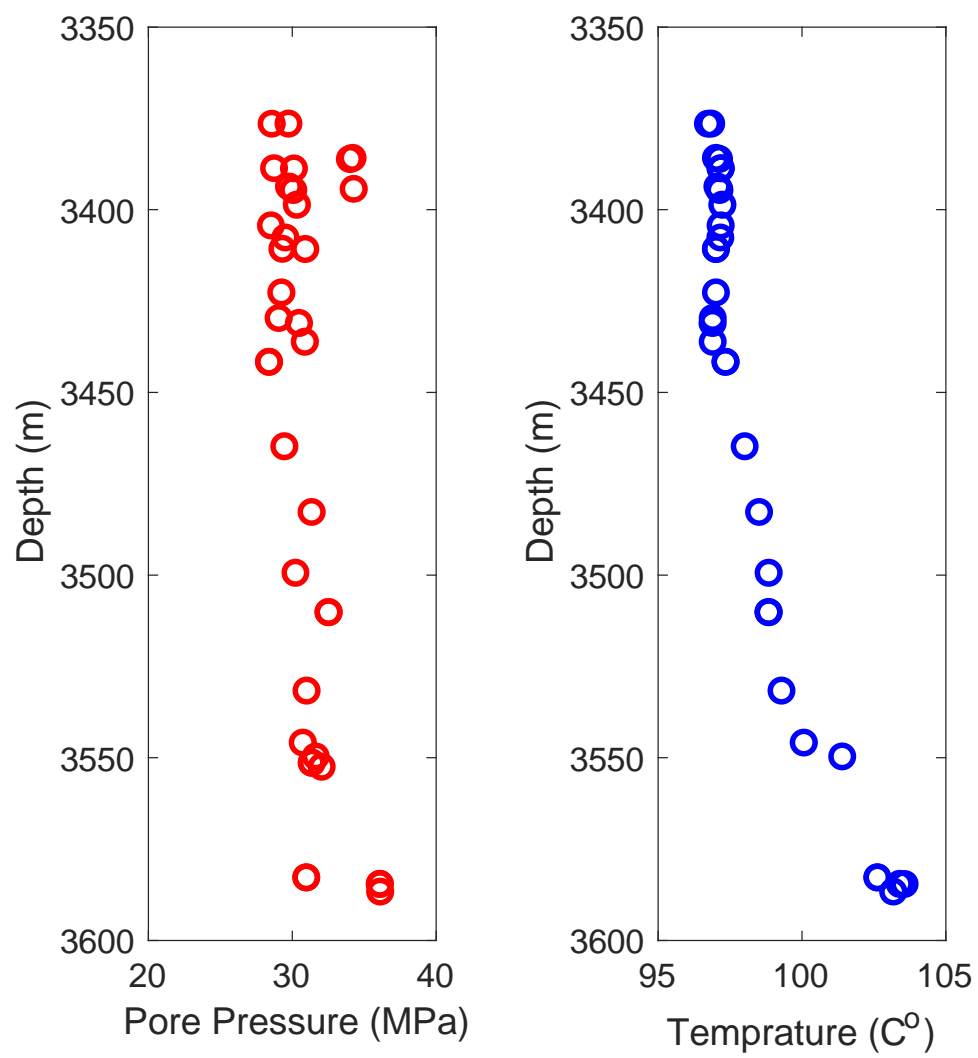

Figure 8: The pore pressure and the temperature variation of the Asmari formation located underneath of Gachsaran formations

According to the studies carried out on the pressure-volume/time curves of LOT tests, the pressure corresponds to the fracture closure would represent the magnitude of the minimum horizontal stress, if the test is done with a fast flow rate and a viscous fluid (Zoback, 2007; Aadnoy and Loyeh, 2011). Considering the duration of the tests shown in Figure 9 , it is clear that the LOT test was done very fast and as such the fracture closure pressure with a value of 10200 psi (72 $\mathrm{MPa}$ ) was considered for the estimation of the minimum horizontal stress. Comparing this value with the magnitude of vertical stress at $3800 \mathrm{~m}$ (i.e., $~ 84 \mathrm{MPa}$ ), it seems that stress regime would be either normal or strike slip at the bottom of Gachsaran formation which is aligned with the results obtained from the poroelastic equations. 
To further calibrate the magnitude of stresses, the stress polygon method was used together with the LOT test data to constrain the magnitude of maximum horizontal stress at $3800 \mathrm{~m}$. The details of the stress polygon method can be found in Zoback, (2007). Figure 10 shows the results obtained for two break-out widths and two strength values according to the break-out failure captured by image logs at the depth of $3800 \mathrm{~m}$.

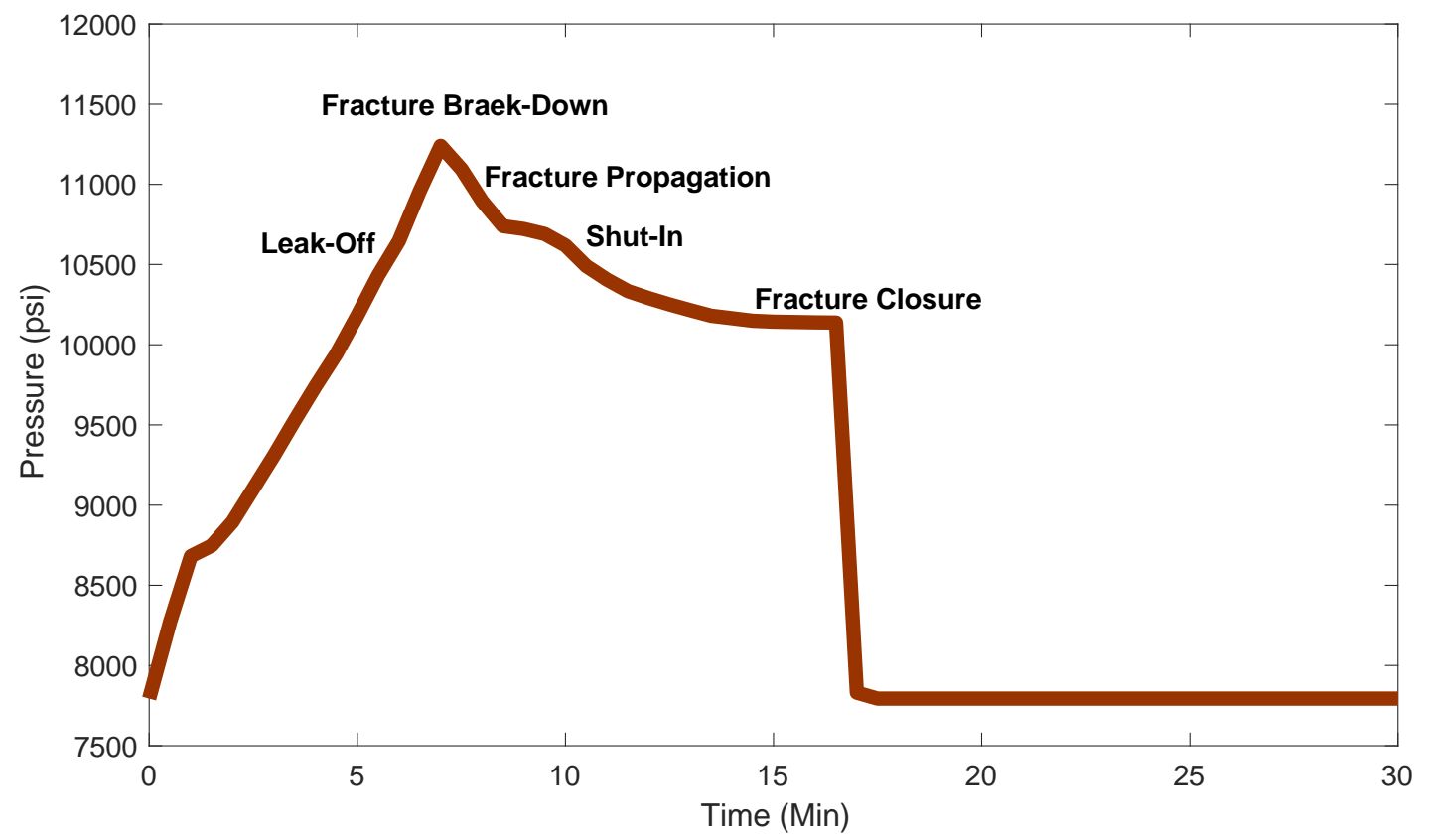

Figure 9: Extended Leak-Off Test (XLOT) carried out at the casing shoe of 3800m in Well A
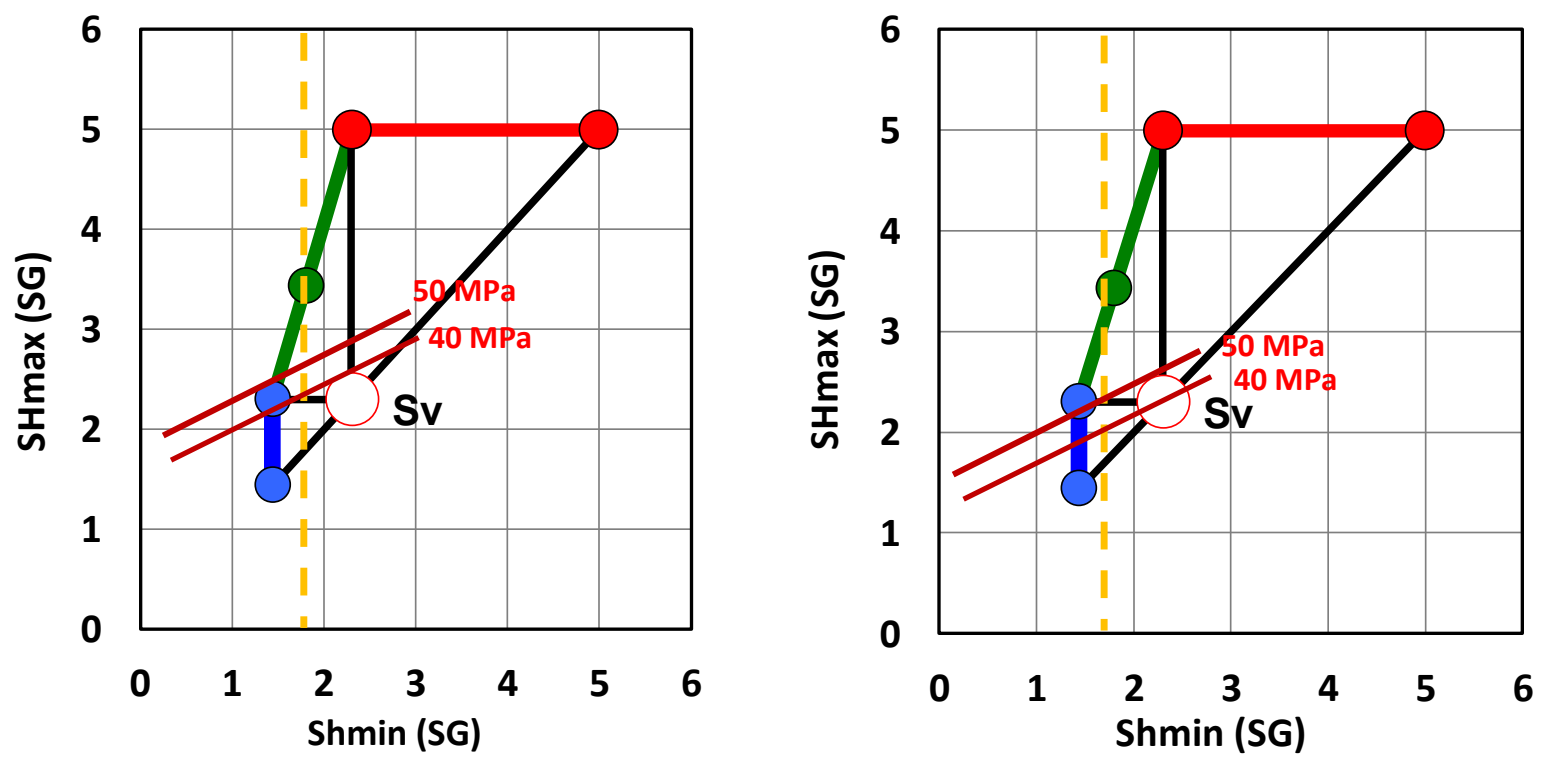

Figure 10: Stress polygon used for the casing shoe of $3800 \mathrm{~m}$ to evaluate the magnitude of maximum horizontal stress at the break-out width of 30 degree (left) and 45 degree (right). Red, green and blue lines respectively represent the boundary of reverse, strike slip and normal faulting regimes. The yellow line shows the magnitude of minimum horizontal stress obtained from the LOT test 
As it is seen in Figure 10, the results obtained from the stress polygon method indicated that the maximum horizontal stress at the depth of $3800 \mathrm{~m}$ would be between 2-2.2 SG (74-82 MPa) which indicates the presence of a normal stress regime at the bottom of Gachsaran formation. This indicates the fact that there is a shift of the stress regime from strike slip $\left(\sigma_{H}>\sigma_{V}>\sigma_{h}\right)$ to normal stress $\left(\sigma_{v}>\sigma_{H}>\sigma_{h}\right)$ in Well $A$, as shown in Figure 7 and 10, which might be due to the presence of salt. This is also aligned with the stress map of Iran, shown in Figure 11, where fields in the southwest close to the Persian Gulf are marked with strike slip faulting regimes. As mentioned earlier, salt can cause local perturbation of in-situ stress magnitudes and rotate their directions. This change in the stress regime may also be linked to the presence of a fault crossed by the Well in the area (Salehi et al., 2009). Therefore, further studies are required to understand the cause of sudden change in the stress regime in this Well.

\subsection{Creep Strain}

To determine the elastic and the initial transient creep responses of anhydrate and halite, Eq. (4) was used by considering the viscosity of different salt types summarised in Table 3 . To evaluate whether or not the steady state (strain softening) deformation of salt rocks had taken place during drilling, the deformation map shown in Figure 5 was used assuming that the melting point of evaporites are $800^{\circ} \mathrm{C}$ and $1400^{\circ} \mathrm{C}$ for halite and anhydrate, respectively (Munson and Dawson, 1979).

Plotting the ratio of equivalent (von-Mises) stress over shear stress against the homologous temperature in the deformation map indicated that the creep stops at the relaxation (elastic/viscoelastic) stage due to the insufficient bottomhole temperature and the short time scale (i.e., less than 5 days) of drilling the salt formation (Gachsaran 6). The primary strain creep obtained from Eq. (4) is plotted for evaporites intervals (Gachsaran 7 and Gachsaran 6 ) in the $5^{\text {th }}$ and $6^{\text {th }}$ tracks of Figure 7.

Table 3: Viscosity of common evaporated rocks (after Weijermars and Jackson, (2014b))

\begin{tabular}{|c|c|c|c|}
\hline Evaporate & Chemical Formula & Viscosity (Pa s) & Reference \\
\hline Halite & $\mathrm{NaCl}$ & $\sim 1 \times 10^{18}$ & van Keken et al. (1993) \\
\hline Anhydrite & $\mathrm{CaSO}_{4}$ & $2.7 \times 10^{19}$ & Zulauf et al. (2009) \\
\hline Carnallite (Wet) & $\mathrm{KMgCl}_{3} \cdot 6 \mathrm{H}_{2} \mathrm{O}$ & $\sim 1 \times 10^{9}$ & Warren (2006) \\
\hline Gypsum (wet) & $\mathrm{CaSO}_{4} \cdot 2 \mathrm{H}_{2} \mathrm{O}$ & $\sim 1 \times 10^{16}$ & Griggs (1940) \\
\hline
\end{tabular}

As it is seen from Figure 7, there is a good agreement between the synthesis model of the borehole geometry created by the estimated strain creep with the deformations and closure of the wellbore wall captured by the calliper logs. To further validate the results, numerical simulation was run to model the behaviour of salt in the wellbore under the given pressure and temperature conditions. This will be discussed in the next section. 


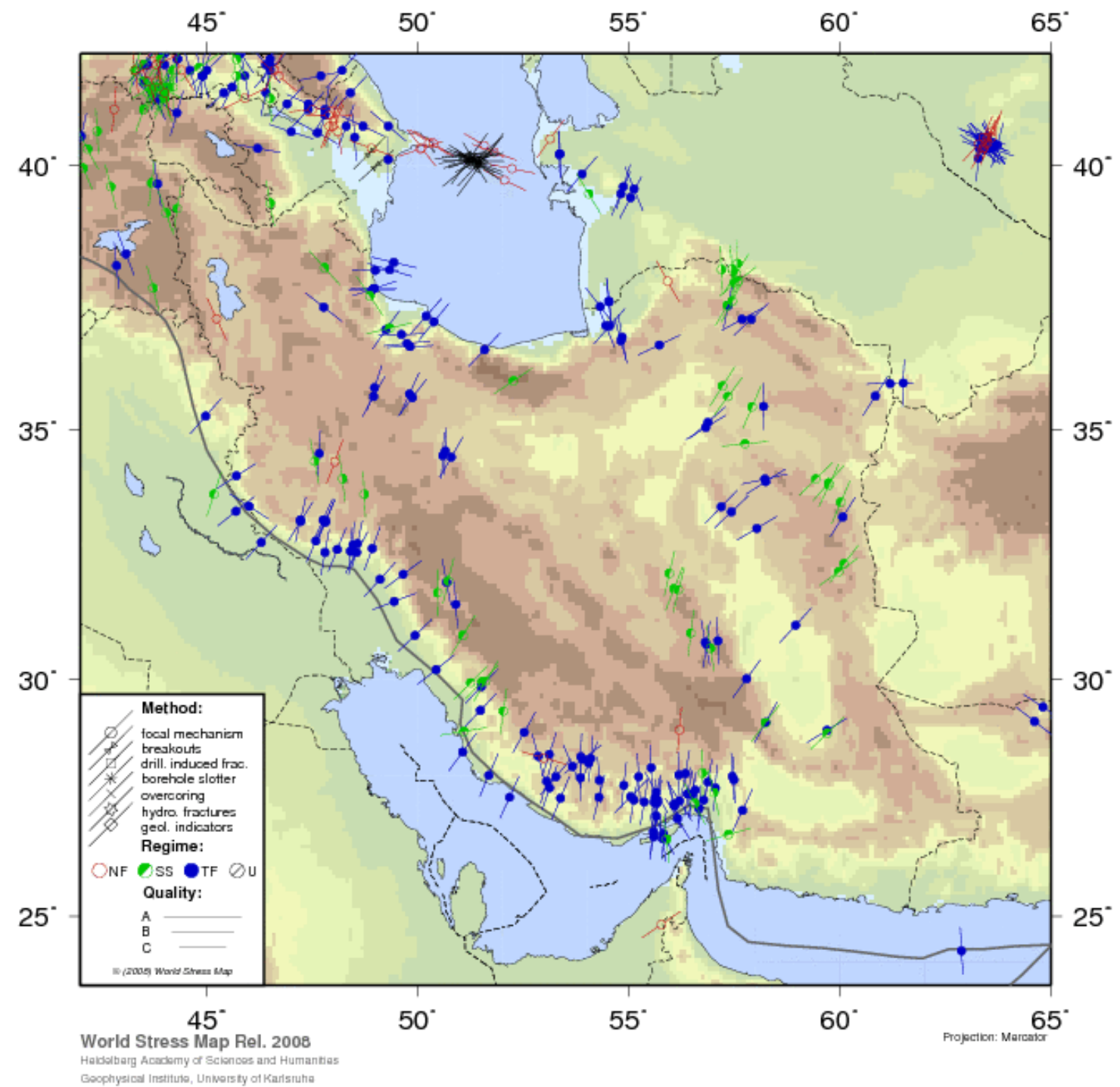

Figure 11: Stress map of Iran indicating the stress regimes and direction of maximum horizontal stress (Heidbach et al., 2008). As depicted, fields located in the south-wet part close to the

Persian Gulf are marked with the strike slip regime

\section{Numerical Modelling}

The numerical modelling of this study was done using ANSYS workbench, which is a commercial finite element software. Considering the fact that salt creep was taking place during drilling and before completion, four formations without completions were modelled as part of this study. The formation elements contain an additional degree of freedom to accommodate pore pressure during simulation. It was assumed that the drilling process imposes different wellbore pressure (mud weight pressure) on the inner surface of each formation to prevent any instability. In this case, the mud weight reported in Table 1 was considered and applied to each formation. Figure 12 shows the geometry of the reference model generated in ANSYS. 

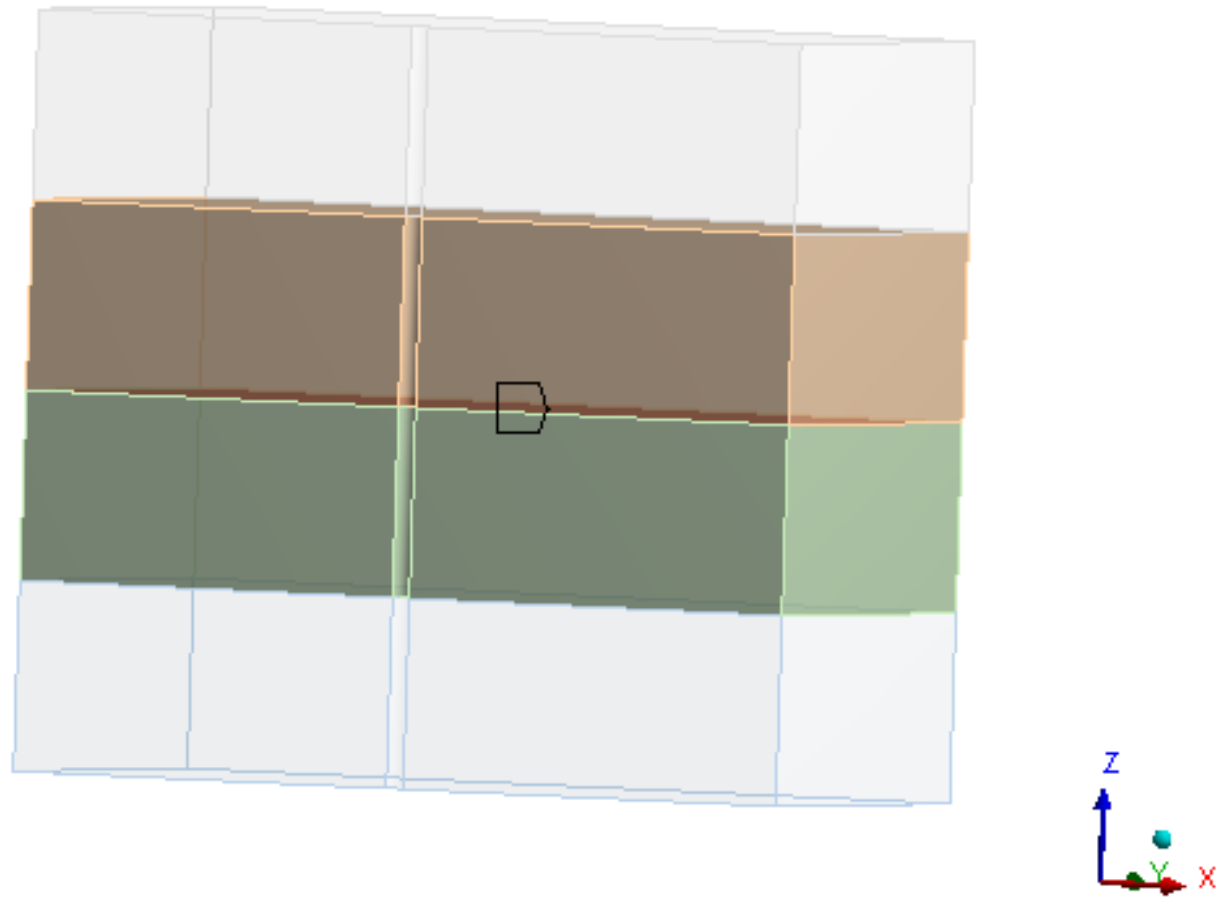

Figure 12: The geometry of the reference numerical model containing four different formations with different geomechanical properties built for the purpose of this study

A rough contact interaction was considered between formations to assess their effect on each other. Aghajari and Mishan formations were considered as poro-elastic formations with DruckerPrager hardening response whereas Gachsaran formations were assumed to show a full creep behaviour, including strain hardening, strain softening and ultimate failure. This was done to examine if the pressure and temperature of the well fulfil a complete creep behaviour or the salt flow would stop before the ultimate failure point. This may also verify the results obtained from the analytical approach presented earlier. To have a more representative result, the elastic and mechanical parameters of each formation were assumed to be temperature dependent based on Figure 6. Last but not least, the in-situ stresses shown in the $4^{\text {th }}$ track of Figure 7 were applied to the outer boundary of the model.

Six degrees of freedom (i.e. no rotation and no displacement at any directions) were considered for the bottom of the model. In order to ensure that the model is large enough to eliminate the boundary effects, a larger model size than the original model was considered. The elements within the range of the original model remained identical for the larger model. The lateral displacements of the models were used for comparison and it was observed that there are 
negligible differences between the accuracy of the bigger and smaller models. In addition, the effect of the mesh sizes on the accuracy of results was evaluated and it was found that current meshes (i.e. tetragonal shape) are the best choices in terms of accuracy and computational time.

\subsection{Creep Induced Stress Analysis}

In this section, the thermo-mechanical analysis involved in the numerical modelling is presented together with their corresponding mathematical equations. The heat transfer was modelled based on the energy-balance equation, expressed as (Carslaw and Jaeger 1959):

$$
\rho C \frac{\partial T}{\partial t}+\nabla \cdot(-\lambda \nabla T)=q
$$

where $\square$ is the density, $C$ is the heat capacity, $\lambda$ is the thermal conductivity, $T$ is the temperature, $q$ is the heat source, and $\nabla$. is the divergence operator.

The stress equilibrium, on the other hand, was written based on the principle of virtual work for the volume under consideration as (Zienkiewicz and Taylor 2005):

$$
\int_{V} \sigma: \delta \varepsilon d V=\int_{S} \gamma \cdot \delta v d S+\int_{V} f . \delta v d V
$$

where $\delta v$ is the virtual velocity field, $\delta M$ is the virtual rate of deformation, $\sigma$ is the surface traction per unit area, and $f$ is the body force per unit volume. This equation can be discretized using a Lagrangian formulation with displacements to give the nodal variable.

The constitutive equation of the solid, under these circumstances, is written as (Hashiguchi, 2014):

$$
d \sigma=E d \varepsilon+\int_{0}^{t}(t-\tau) \frac{d \varepsilon}{d \tau} d \tau
$$

where is the stress, $\varepsilon$ is the strain, $E$ is the material stiffness, and $\tau$ is the relaxation time. The constitutive equation corresponding to the salt behaviour is solved by considering the following stages.

1) Reaching the initial geostatic equilibrium, the displacement $\Omega_{i}$ and stress i are solved, as the initial values based on the following equations:

$$
\begin{aligned}
& K \delta_{i}=F \\
& \sigma_{i}=D B \delta_{i}
\end{aligned}
$$

where $K$ is the stiffness matrix, $F$ is the equivalent nodal force, $D$ is the elasticity matrix, and $B$ is the geometric stiffness matrix.

2) Assuming that the stress stays the same during each increment, $t+\Delta t$, the creep-strain increment, $\Delta \varepsilon_{t}^{c}$, during each time interval, $\Delta t$, is calculated using Eq.(10).

$$
\left(\Delta \varepsilon_{t}^{c}\right)_{\Delta t}=\Delta t\left(\varepsilon_{t}^{\cdot}\right)
$$

where $\dot{\varepsilon}_{t}$ is the creep rate at the time $t$, expressed as $\dot{\varepsilon}_{t}=\left(\dot{\varepsilon}_{1}, \dot{\varepsilon}_{2}, \dot{\varepsilon}_{3}\right)$ and obtained by using the following equations:

$$
\dot{\varepsilon}_{1}=\frac{\dot{\varepsilon}}{\sigma_{e f f}}\left[\sigma_{1}-\frac{1}{2}\left(\sigma_{2}+\sigma_{3}\right)\right]
$$




$$
\begin{aligned}
& \dot{\varepsilon_{2}}=\frac{\dot{\varepsilon}}{\sigma_{e f f}}\left[\sigma_{2}-\frac{1}{2}\left(\sigma_{1}+\sigma_{3}\right)\right] \\
& \dot{\varepsilon_{3}}=\frac{\dot{\varepsilon}}{\sigma_{e f f}}\left[\sigma_{3}-\frac{1}{2}\left(\sigma_{1}+\sigma_{2}\right)\right]
\end{aligned}
$$

In these equations, the effective stress is obtained as (Irgens, 2008):

$$
\sigma_{e f f}=\frac{1}{\sqrt{2}}\left[\left(\sigma_{1}-\sigma_{2}\right)^{2}+\left(\sigma_{2}-\sigma_{3}\right)^{2}+\left(\sigma_{1}-\sigma_{3}\right)^{2}+6\left(\tau_{12}^{2}+\tau_{23}^{2}+\tau_{13}^{2}\right]^{\frac{1}{2}}\right.
$$

The nodal force, $\Delta F_{c}(t)$, in each time interval can then be obtained as:

$$
\Delta F_{c}(t)=\int_{\Omega}(B)^{T}(D)\left(\Delta \varepsilon_{t}^{c}\right) d \Omega
$$

which is applied to the entire salt-formation and gives the following equilibrium:

$$
K\left(\Delta \delta^{c}\right)_{t}=\Delta F_{c}(t)
$$

The creep-induced displacement, $\Delta \delta^{c}$, during each increment $\Delta t$, is then determined and the corresponding stress increment is calculated using the following equation:

$$
\left(\Delta \sigma^{c}\right)_{t}=D\left[(B)\left(\Delta \delta^{c}\right)_{t}-\left(\Delta \varepsilon_{t}^{c}\right)\right]
$$

Adding $\Delta \delta^{c}$ and $\Delta \sigma^{c}$ to the initial displacement, and the stress calculated at the geostress stage, the variation of stress and the displacement can be calculated over time as:

$$
\begin{aligned}
\sigma_{t+\Delta t} & =\sigma_{t}+\left(\Delta \sigma^{C}\right)_{t} \\
\delta_{t+\Delta t} & =\delta_{t}+\left(\Delta \delta^{C}\right)_{t}
\end{aligned}
$$

This coupled system of equations can be resolved using Newton-Raphson technique (Ypma, 1995) and a linear solver, which can consider all the possible solutions, where the variables are updated at the end of each time increment.

\subsection{Results}

Considering the fact that the analytical method presented earlier provided a good match with the wellbore closure captured by the calliper log, numerical simulations were run to examine the accuracy of the result. Figures 13 and 14 display the iso-surface of the normal and minimum principal stresses obtained after modelling while Figure 15 depicts the strain rate-time curve of the finite element model.

As it is seen from Figures 13 and 14, in the formations without creep behaviour, the maximum stress is distributed within the contact surfaces between two adjacent formations due to the applied stresses (reaction force) but there is not any sign of deformation. In the last formation, which is the Gachsaran salt formation, though, significant changes and deformations due to the 
applied stress were observed. Looking at Figures 13 and 14, one can conclude that the maximum deformation is induced around the borehole in the salt (halite) formation with a pattern similar to what has been captured by the calliper log. Considering the plot of the strain-time shown in Figure 15, it seems that the creep strain will not reach the steady state (strain softening) stage during the first five days of drilling due to insufficient pressure and temperature. According to these results, the viscoelastic behaviour of salt appears to be the trigger for the borehole failure during five days of drilling in the salt formation. This was the very same conclusion made by the analytical model. Figure 16 shows the variation of the equivalent elastic strain in the model, particularly in the salt formation.

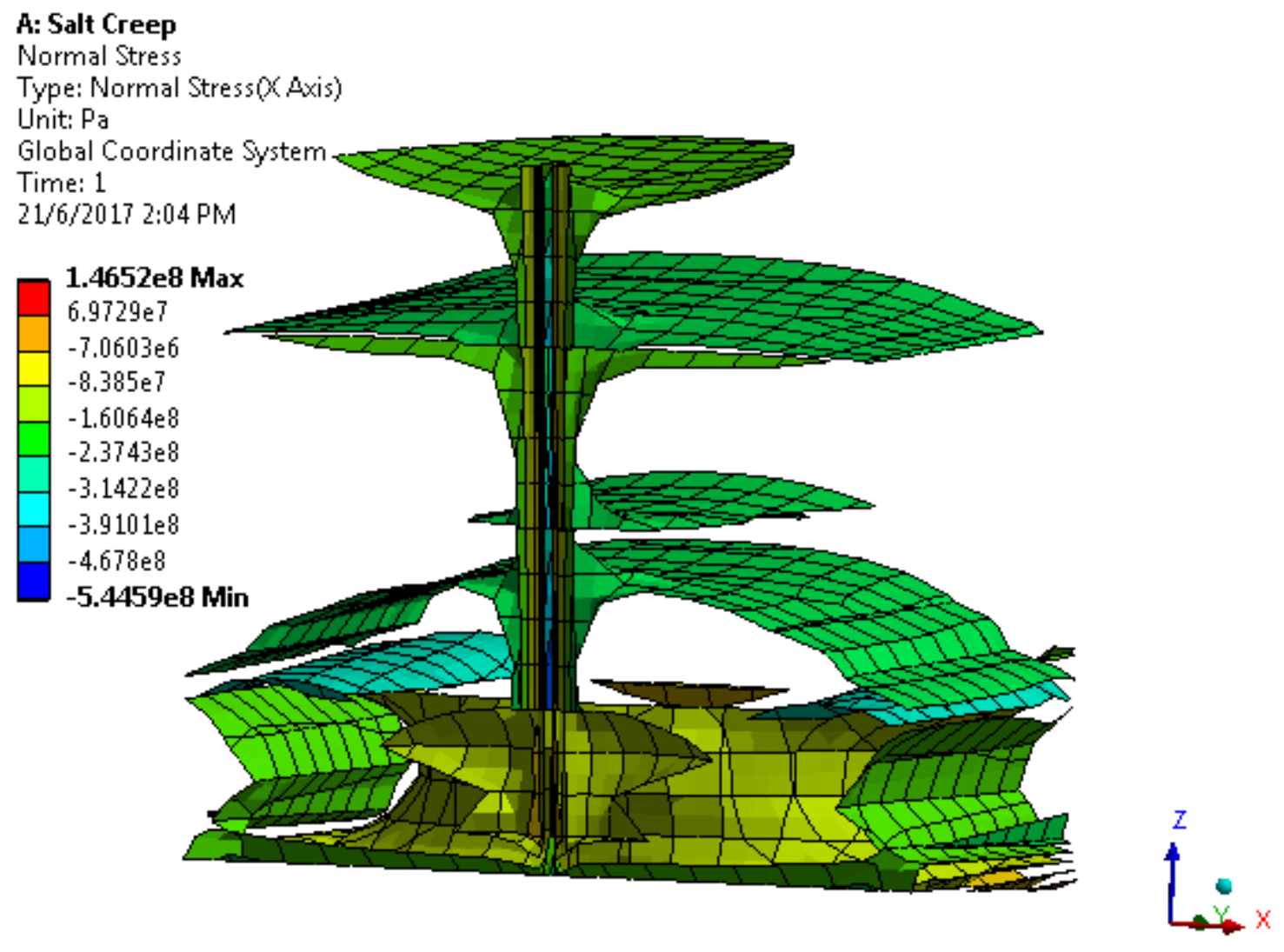

Figure 13: Changes in the variation of the normal stress in the model Looking at the variation of the elastic strain in the model, the strain rate predicted by the numerical analysis and the one provided earlier from the analytical solutions show a close agreement.

\section{Discussions}

Salt may exhibit different behaviours depending on the differential pressure and temperature of the bottom hole conditions. It is known that the tertiary creep (rupture) often occurs in the cavern sites, where cyclic loading is applied due to the fluid injection. Thus, according to the 
studies carried out so far, primary (strain hardening) and secondary (strain softening) creep may be experienced in salt during drilling, depending on the pressure, temperature, type of salt and moisture of formations drilled. In this study, following the concept of the damage mechanics, an approach was presented to determine the strain induced by salt creep during drilling. The KelvinVoigt viscoelastic solid was modified by adding the shear modulus to its original equation for giving a more representative result. The results were compared with a numerical model built to simulate the creep behaviour of the salt formation by applying the pressure and temperature of the subsurface layers. Figure 15 compares the strain rate estimated by the analytical and numerical models.
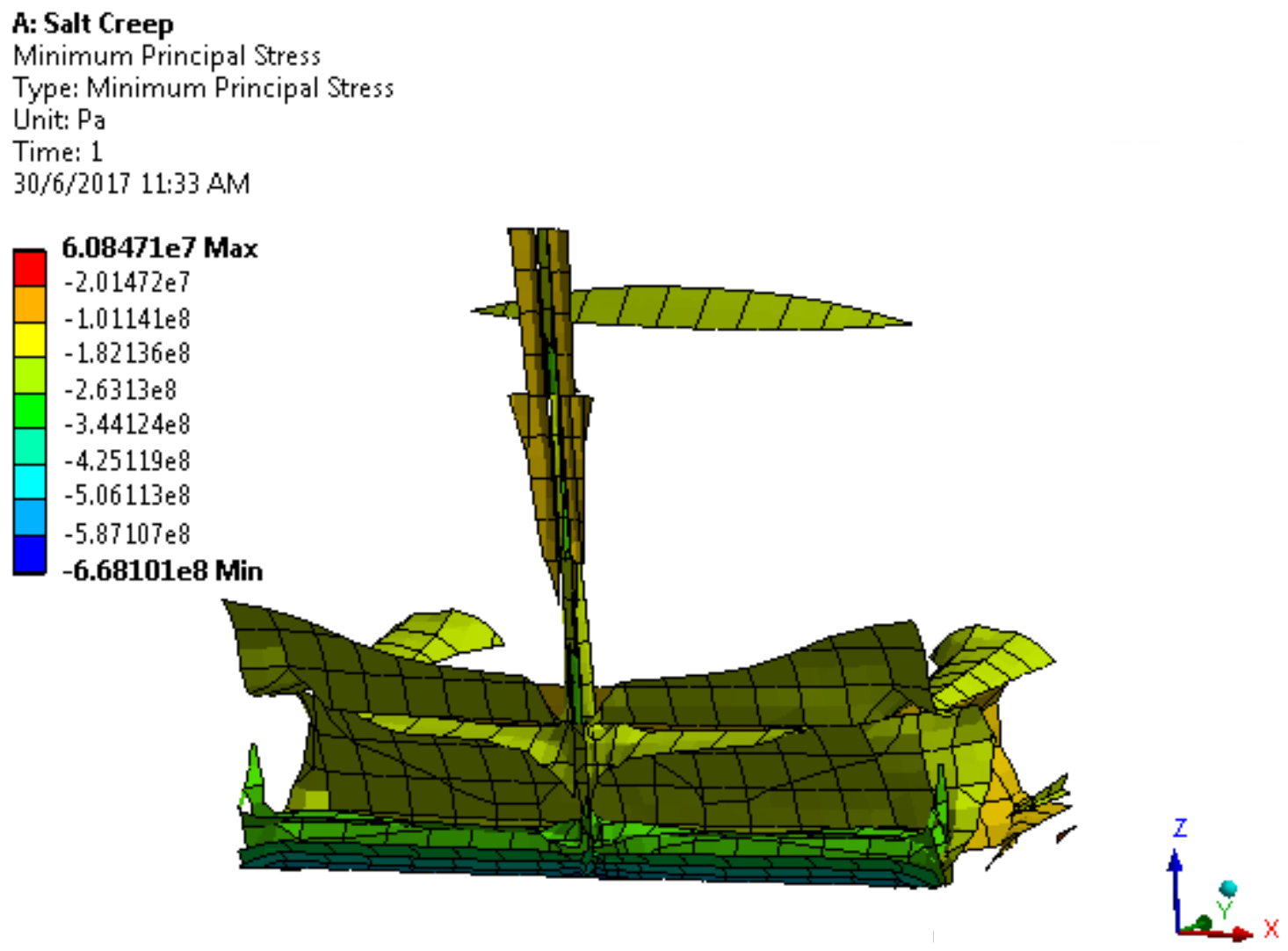

Figure 14: Changes in the variation of the minimum principal stress in the model 


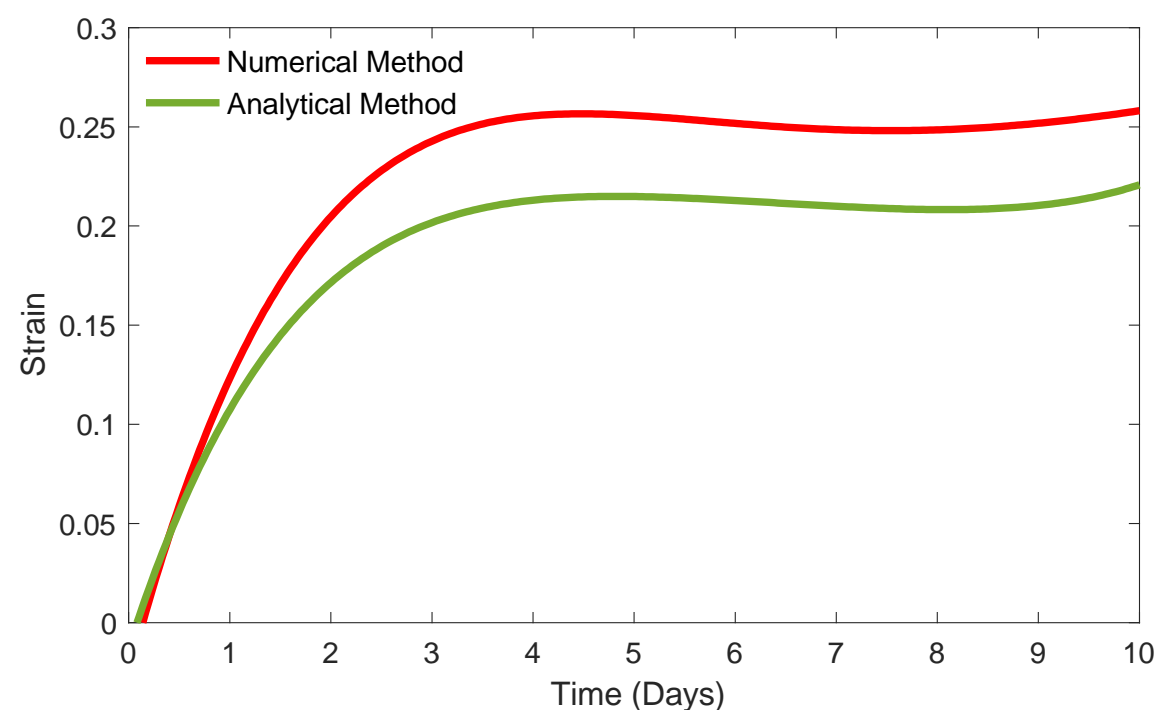

Figure 15: Comparison of the strain rate obtained from the analytical and numerical modelling

A: Salt Creep

Equivalent Elastic Strain

Type: Equivalent Elastic Strain

Unit: $\mathrm{m} / \mathrm{m}$

Time: 1

21/6/2017 2:02 PM

$0.58742 \mathrm{Max}$

0.52235

0.45727

0.3922

0.32712

0.26205

0.19697

0.1319

0.06682

0.0017451 Min
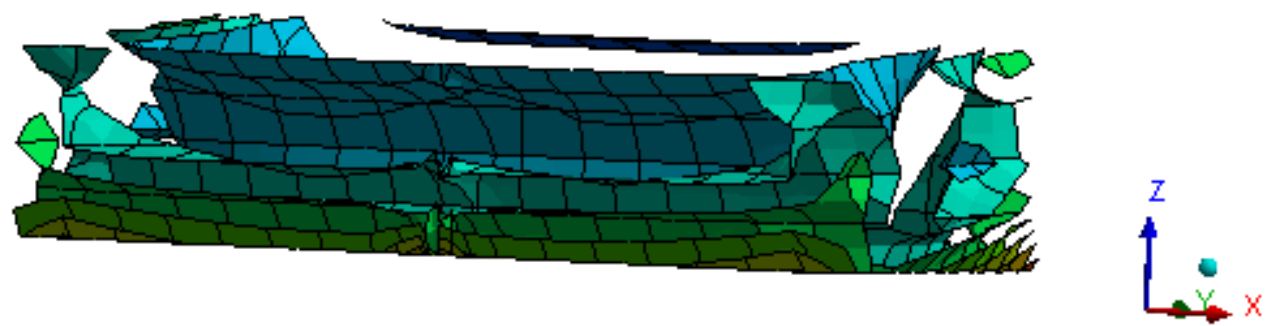

Figure 16: Variations of the equivalent elastic strain in the model 
Salt Behaviour Under Different Stress Anisotropy Conditions

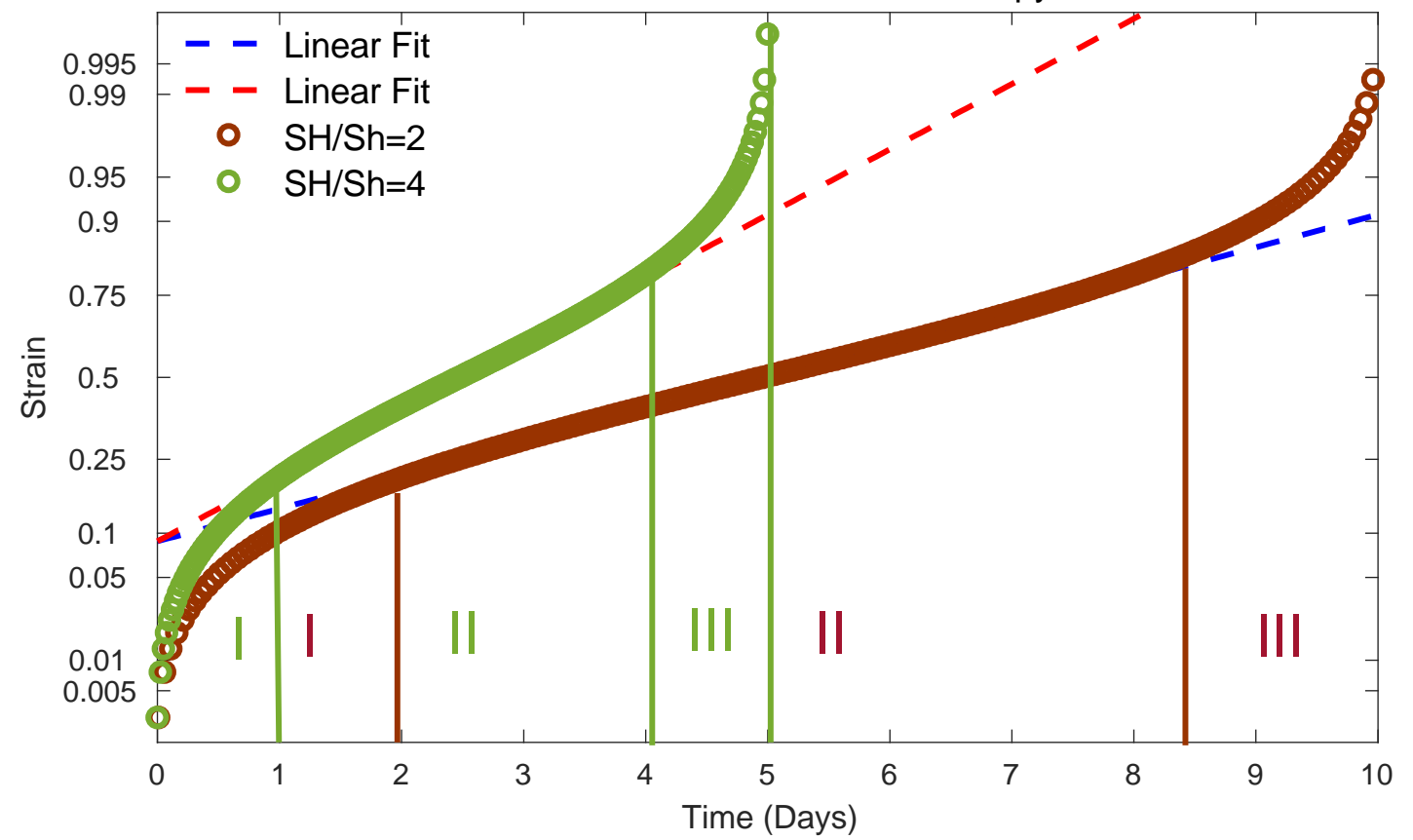

Figure 17: Salt behaviour under different stress anisotropy (SH/Sh) conditions and a same temperature

As it is seen from figure 15, salt mainly exhibits viscoelastic behaviour during five days of drilling due to the low temperature condition and fast drilling operations. The strain rate predicted using both methods are within the same range but some differences are observed in the values due to the nature of these two methods. Having said that, one may conclude that the approach presented has sufficient accuracy in the modelling of the strain rate induced by the presalt sheet in the well.

There was, however, another important conclusion drawn by the numerical modelling for the effect of stress anisotropy on the salt behaviours. As mentioned earlier, the assumption often made for the salt is that the stress anisotropy does not exist in the salt intervals. On the country, the results obtained from the numerical modelling indicated that salt can sustain shear stress posed by differential stress to some extent and changes in the stress anisotropy will severely affect the salt behaviour as shown in Figure 17. As a matter of fact, the larger the stress anisotropy is, the faster the salt creep would be and the higher the chance of wellbore closure in a very short period of time.

\section{Conclusions}

In this paper, an approach was presented based on damage mechanics to determine the strain rate induced at different stages of creep. The results obtained, which were based on a real case study from the Southern part of Iran, indicated that the presented analytical model can determine the stage and the rate of creep as it is developing during drilling. The results were 
calibrated against a finite element model, where it was found that viscoelastic behaviour is observed from the salt under the existing pressure and temperature of the wellbore. It could also be due to the fast drilling of the salt section which took only 5 days in the presented case study. Although the results seem promising, more studies are required to further validate the application of the proposed method.

\section{References}

Aadnoy, B. S., Cooper, L., Miska, S. Z., Mitchell, R. F., Payne, M. L., 2009. Advanced Drilling and Well Technology, Society of Petroleum Engineering, Texas, USA

Aadnøy, B.S., Looyeh, R., 2011. Petroleum rock mechanics: Drilling operations and well design. Gulf Professional Publishing, Oxford.

Alavi, M. (2004) Regional Stratigraphy of the Zagros Fold-Thrust Belt of Iran and Its Proforeland Evolution. Am J Sci, 304, 1-20. http://dx.doi.org/10.2475/ajs.304.1.1

Andrade, DA C. 1910, On the viscous flow of metals, and allied phenomena, Proc. R. Soc. Lond., vol. ALXXXIV, pp. $1-12,1910$.

Bahroudi, A. and Koyi, H. 2003. Effect of Ductile and Frictional Décollements on Style of Extension. J Struct Geol, 25, 1401-1423. http://dx.doi.org/10.1016/S0191-8141(02)00201-8

Barton, C.A., Catillo, D.A., Moss, D.B., Peska, P., Zoback, M.D., 1988. Charactering the full stress tensor based on observation of drilling induced wellbore failures vertical and inclined borehole leading to improved wellbore stability and permeability prediction, APPEA Journal. 466-488.

Berard, T., B. K. Sinha, P. van Ruth, T. Dance, Z. John, and C. P. Tan, 2008, Stress estimation at the Otway CO2 storage site, Australia: Presented at the SPE Asia Pacific Oil and Gas Conference and Exhibition, 1-26.

Bratton, T., V. Bricout, R. Lam, T. Plona, B. K. Sinha, K. Tagbor, A. Venkitaraman, and T. Borbas, 2004, Rock strength parameters from annular pressure while drilling and dipole sonic dispersion analysis: Presented at the SPWLA 45th Annual Logging Symposium, Society of Petrophysicists \& Well Log Analysts, 1-14. 10.1190/1.2231107

Carcione, J.M., Helle, H.B., Gangi, A.F., 2006. Theory of borehole stability when drilling through salt formations, Geophysics, 71, F31-F47.

Carslaw, H. S. and Jaeger, J. C. 1959. Conduction of Heat in Solids, second edition. Oxford, UK: Oxford University Press.

Chatar, C., Mohan, S.\& Imler, M., 2010. Overcoming a difficult salt drilling environment in the Gulf of Mexico: a case study, in Paper IADC/SPE 128192 presented at the IADC/SPE Drilling Conference and Exhibition, New Orleans, LA, USA, pp. 1-12.

Cheatham, J. B., Jr., and J. W. McEver, 1964, Behavior of casing subjected to salt loading, J Petrol Tech, v. 16, p. 1069-1075. 
Chitale, V., Alabi, G., Kasten, R. et al. 2014. Learning from Deployment of a Variety of Modern Petrophysical Formation Evaluation Technologies and Techniques for Characterization of a Pre-Salt Carbonate Reservoir: Case Study from Campos Basin, Brazil. Presented at the SPWLA 55th Annual Logging Symposium, Abu Dhabi, 18-22 May. SPWLA-2014-G.

Du, C., Yang, C., Yuanfeng, Y., Li, Z. \& Chen, J., 2012. Mechanical behaviour of deep rock salt under the operational conditions of gas storage, Int. J. Earth Sci. Eng., 5(6), 1670-1676.

Dusseault, M.B., Bruno, M.S., Barrera, J., 2001. Casing shear: causes cases cures. SPE Drill. Complet. 16 (02), 98-107

Dusseault, M. B., V. Maury, F. Sanfilippo, and F. J. Santarelli, 2004, Drilling through salt: Constitutive behavior and drilling strategies, American Association of Rock Mechanics, North American Rock Mechanics Association, 04-608, p. 1-13.

Dyson, B. F. and McLean, M. 1998, Microstructural evolution and its effects on the creep performance of high temperature alloys, in Microstructural Stability of Creep Resistant Alloys for High Temperature Plant Applications, pp. 371 - 393, Cambridge: Cambridge University Press

Eaton, B.A. 1975. The Equation for Geopressure Prediction from Well Logs. Society of Petroleum Engineers of AIME. paper SPE 5544.

Fjaer, E., Holt, R.M., Hordrud, P., Raaen, A.M., Risnes, R., 2008. Petroleum related rock Mechanic, Dev. Petrol. Sci, Elsevier.

Fossum, A. F., and J. T. Fredrich, 2002, Salt mechanics primer for near-salt and sub-salt Deepwater Gulf of Mexico field developments: Albuquerque, New Mexico, and Livermore, California, Sandia National Laboratories, Sandia Report SAND2002-2063, 67 p.

Frost, H. J. and Ashby, M. F. 1982, Deformation Mechanism Maps. Oxford: Pergamon Press

Garland, J., Neilson, J., Laubach, S. E. et al. 2012. Advances in Carbonate Exploration and Reservoir Analysis. Geol. Soc. Lond. Spec. Pub. 370 (1): 1-15. http://dx.doi.org/10.1144/SP370.15

Gholami. R., Aadnoy, B., Leong, Y. Foon, Elochukwu, H. 2017. A methodology for wellbore stability analysis in anisotropic formations: A case study from the Canning Basin, Western Australia, $J$ Nat Gas Sci Eng, 37, 341-360

Gholami, R., Moradzadeh, A., Rasouli, V., Hanachic, J., 2014. Practical application of failure criteria in determining safe mud weight windows in drilling operations. J. Rock. Mech Geotech. Eng. 6(1),13-25. http://dx.doi.org/10.1016/j. jrmge.2013.11.002.

Gholami, R., Rabie, M., Rasouli, V. Aadnoy, B., 2015a. Application of quantitate risk assessment in wellbore stability analysis, J Petrol Sci. Eng. 135, 185-200

Gholami. R., Rasouli, V., Aadnoy, B., Mohammadi, R. 2015b. Application of in situ stress estimation methods in wellbore stability analysis under isotropic and anisotropic conditions, J Geophys. Eng., 12, 657-673 
Golubev, A.A., Rabinovich, G.Y., 1976. Resultaty primeneia appartury akusticeskogo karotasa dlja predeleina proconstych svoistv gornych porod na mestorosdeniaach tverdych isjopaemych. Prikl. Geofiz. Moskva 73, 109-116.

Gorash, Y. 2008. Development of a creep-damage model for non-isothermal long-term strength analysis of high-temperature components operating in a wide stress range, PhD thesis, The Martin Luther University Halle-Wittenberg, Netherland

Gorjian, M., Memarian, H., Moosavi, M., Mehrgini, B., 2013. Dynamic properties of anhydrites, marls and salts of the Gachsaran evaporitic formation, Iran. J Geophy Eng, 10 (1), 015001.

Graham, A. and Walles, K. F. A., 1961, On the extrapolation of creep data, NGTE Report R247, 1961.

Greenhalgh, J., Borsato, R., Mathew, F. et al. 2012. Pre-Salt Hydrocarbon Prospectively in the Kwanza and Benguela Basins of Offshore Angola. Presented at the 2012 SEG Annual Meeting, Las Vegas, Nevada, 4-9 November. SEG-2012-1084.

Gutierrez, M.A., Braunsdorf, N.R., Couzens, B.A., Dec., 2006. Calibration and ranking of porepressure prediction models. The Leading Edge, 1516-1523.

Hashiguchi, K. 2014. Elastoplasticity Theory. Vol. 69, Lecture Notes in Applied and Computational Mechanics. Springer-Verlag Berlin Heidelberg.

Horsrud. 2001. Estimating mechanical properties of shale from empirical correlations, SPE Drilling \& Completion, SPE 56017

Hubbert, M.K., Willis, D.G.1957. Mechanics of hydraulic fracturing. Pet. Trans. AIME 210, 153163.

Hudec, M. R., M. P. A. Jackson, and D. D. Schultz-Ela, 2009. The paradox of minibasin subsidence into salt: Clues to the evolution of crustal basins: Geological Society of America Bulletin, v. 121 , p. 201-221

Irgens, F. 2008. Continuum Mechanics. Berlin: Springer

Israel, R.R., D’Ambrosio, P., Leavitt, A.D., Shaughnessey, J.M. Sanclemente, J., 2008. Challenges of directional drilling through salt in deep water Gulf of Mexico, in Paper 112669 Presented at IADC/SPE Drilling Conference, March 4-6, Orlando, FL, USA, pp. 1-19.

Kirsch, G., 1898. Die Theorie der Elastizit“at und die Bedurfnisse der Festigkeitslehre, Zeitschrift des Vereines deutscher Ingenieure, 42, 797-807

Lifshitz, I. M. 1963, On the theory of diffusion-viscous flow of polycrystalline bodies, Soviet Physics. J Exp Theor Physics, vol. 17, pp. $909-920$

Liu, X., Birchwood, R. \& Hooyman, P.J., 2011. A new analytical solution from wellbore creep in soft sediments and salt, ARMA, 11-383.

Matthews, W.R., and Kelly, J., 1967. How to predict formation pressure and fracture gradient? Oil. Gas. J, 92-106. 
Mehrgini, B., Memarian, H., Dusseault, M. B., Ghavidel, A., Heydarizadeh, M. 2016, Geomechanical characteristics of common reservoir caprock in Iran (Gachsaran Formation), experimental and statistical analysis, J Nat Gas Sci Eng, 34, 898-907

Meyers and Chawla (1999): Section 13.10 of Mechanical Behaviors of Materials, Mechanical behavior of Materials, 570-580. Prentice Hall, Inc.

Molnar, M. (2006) Tertiary Development of the Zagros Mountains, Geol 418-Earth History

Munson, D. E., Dawson, P.R., 1979. Constitutive model for the low temperature creep of salt, Sandia Laboratory report, SAND-79-1853

Rasouli, V., Zacharia, J., and Elike, M. 2011. The influence of perturbed stresses near faults on drilling strategy: A case study in Blacktip field, North Australia. J. Petrol. Sci. Eng., 76: 37-50.

Rios, A., and J. Roegiers, 2012, Dilatancy criterion applied for borehole stability during drilling salt formations: Society of Petroleum Engineers Latin American and Caribbean Petroleum Engineering Conference, Mexico City, Mexico, April 16-18, 2012, SPE Paper 153627, 14 p.

Rolf, B., Mohammed, W., Mohsen, P., 2006. A preliminary Study of Casing Collapse in Iran Hydroquest Report. Schlumberger Oil Company.

Salehi S, Hareland G, Khademi Dehkordi K, Ganji M, Abdollahi M (2009) Casing collapse risk assessment and depth prediction with a neural network system approach. J Petrol Sci Eng 69:156-162

Schoenherr, J., J. L. Urai, P. A. Kukla, R. Littke, Z. Schléder, J.-M. Larroque, M. J. Newall, N. Al-Abry, H. A. Al-Siyabi, and Z. Rawahi, 2007, Limits to the sealing capacity of halite: A case study of the infra-Cambrian Ara Salt from the South Oman salt basin: AAPG Bulletin, v. 91, p. 1541-1557, doi: 10.1306/06200706122.

Sherby, O. D. and Burke, P. M. 1967, Mechanical behaviour of crystalline solids at elevated temperature, Prog. Mater. Sci., 13 (7), pp. 325 - 390

Thompson, D. L., Stilwell, J. D., and Hall, M. 2015. Lacustrine Carbonate Reservoirs from Early Cretaceous Rift Lakes of Western Gondwana: Pre-Salt Coquinas of Brazil and West Africa. Gondwana Res. 28 (1): 26-51. http://dx.doi.org/10.1016/j.gr.2014.12.005

Wang, H.F., 2000. Theory of Linear Poroelasticity, Princeton University Press. Princeton

Weijermars, R. T. P., M. P. A. Jackson, 2014b, Predicting the depth of viscous stress peaks in moving salt sheets: Conceptual framework and implications for drilling, AAPG Bulletin, v. 98 (5), pp. 911-945

Weijermars, R. T. P., M. P. A. Jackson, and T. Dooley, 2014a, Quantifying drag on wellbore casings in moving salt sheets, Geophy J Int, v. 196, no. 1, p. 279-290.

Willson, S.M. Fredrich, J.T., 2005. Geomechanics considerations for through- and near-salt well design, in Paper SPE 95621 Presented at the SPE Annual Technical Conference and Exhibition, October 9-12, Dallas, TX, pp. 1-17.

Ypma, T. J. 1995 Historical Development of the Newton-Raphson Method. SIAM Rev. 37 (4): $531-$ 551. http://dx.doi.org/10.1137/1037125. 
Zhang, J. 2011. Pore pressure prediction from well logs: Methods, modifications, and new approaches, Earth-Sci. Rev, 108, 50-63

Zhang, J., Standifird,W. Lenamond, C., 2008. Casing ultra-deep ultra-long salt sections in deep water: a case study for failure diagnosis and risk mitigation in record-depth well, in Paper SPE 114273 Presented at the SPE Annual Technical Conference and Exhibition, pp. 129-152.

Zienkiewicz, O. C. and Taylor, R. L. 2005. The Finite Element Method, fifth edition. London: Elsevier

Zoback, M., D., 2007. Reservoir Geomechanic. Cambridge University Press.

Zoback, M.D., Barton, C.A., Brudy, M., Castillo, D.A., Finkbeiner, T., Grollimund, B.R., Moos, D.B., Peska, P., Ward, C.D., Wiprut, D.J. 2003 Determination of stress orientation and magnitude in deep wells. Int J Rock Mech Min Sci, 40, 1049e1076

Zoveidavianpoor, M., Samsuri, A., Shadizadeh, S.R., 2012. Development of fuzzy system model for candidate-well selection for hydraulic fracturing in a carbonate reservoir. In: SPE Oil and Gas India Conference and Exhibition. 